\title{
Measurement of In-Room Impact Noise Reduction
}

\author{
A. Elliott \\ Acoustic Research Centre, University of Salford, The Crescent, Greater Manchester, M5 4WT \\ a.s.elliott@salford.ac.uk
}

\begin{abstract}
There are well-established measurement standards for the rating of impact noise reduction provided by floor coverings in relation to structurally transmitted impact noise (BS EN ISO 10140-3 and ASTM E492 are widely used in Europe and North America Respectively). Standardisation for "in-room" impact noise transmitted by an airborne path is however less well established. At the current time the standard used for rating the "in-room" impact sound reduction is BS EN 16205:2013 which focusses primarily on walking noise as the impact source. This standard employs the same tapping machine used for impact improvement testing in BS EN ISO 10140-3 and this has been found not to be ideal due to the mechanical noise it produces and because it is not fully representative of the walking loads that the standard aims to address. There is currently no standard that deals with "in room" impact noise from falling objects which may be a greater concern than walking noise, for example in a healthcare or education setting. Thus, presented in the paper are the findings from a large measurement survey conducted to investigate the influence of impactor mass, hardness and velocity on measured "in room" impact noise reductions. Other measurands such as the reduction in impact force and floor acceleration are also considered. It is discussed in the paper how 'In-room' impact noise differs from transmitted impact noise and this is demonstrated by performing a transfer path analysis to separate out the impact noise contributions from a falling object and from the floor. The key finding of the study is that the whilst the impact noise reduction achieved by different floor coverings varies wildly for different impactor types the rank order of the floor coverings tested in terms of Impact noise reduction did not. Thus, the ideal test method may not be the one that simulates best the type of impacts a floor is likely to be subjected to, but rather, it ought to be the one that gives the biggest differences between similar floor coverings so as to highlight most clearly the differences between them.
\end{abstract}

\section{Introduction}

The built-environment must foster good acoustics to support the activities that take place within a space. For example, a hospital must promote a peaceful atmosphere to allow rest and healing for the patients, and to allow staff to communicate with the patients, other staff, and to hear medical alerts. Similarly, the acoustics of a classroom must allow the teacher to communicate effectively with students positioned around the classroom, 
whilst not reinforcing any distracting background noise. The acoustic ratings associated with floor coverings must therefore cover a broad range of scenarios and aim to be representative of all noise sources and environments in order that product comparisons can be made in a fair and transparent way.

At the current time floor coverings are most commonly rated in terms of their impact noise reduction according to BS EN ISO 10140-3 [1], employing also BS EN ISO 717-2 [2] to provide a convenient single number rating; see also ASTM E492 [3] and ASTM E2179 [4] which are the most widely used approaches in North America. These particular tests [1] are intended to give a simple measure of the impact noise reduction that might be expected in adjacent rooms or on lower floors when a particular floor covering is used. Increasingly however, the noise within the room itself is also becoming of interest in addition to what is transmitted through the floor; for example, in healthcare environments [5]. The approach described in [1] may not in some cases be the best indicator of performance in this respect (nor is it intended to be), because any airborne noise produced by the impacting object itself (acceleration, ringing or air ejection noise) would not be taken into account.

A recently published, but less well-established, European standard EN 16205 [6] aims at addressing the issue of rating "in-room" impact noise reduction in a similar way to BS EN ISO 10140-3 [1], using the same ISO standard tapping machine. However, a round robin investigation involving 17 laboratories found that the approach cannot be used to rate the best performing floor coverings in terms of impact noise reduction because of the noise generated by the tapping machine itself [7]. Another significant issue with the EN 16205 test is thought to be that the ISO standard tapping machine is not representative of all falling objects in terms of the noise the hammers produce, the hardness, or the geometry and impact velocity of the hammer faces. Note also that the hammers of standard tapping machines exhibit little in the way of ringing noise in the frequency range of interest, as might be the case for many types of falling objects encountered, e.g. in hospitals or schools. Nor is it representative in terms of contact area, hardness, or acceleration noise produced by footfall [8]. For these reasons, it is widely accepted by both academia and industry that further study is required to investigate the most suitable means of impacting floors for both, in-room and transmitted impact noise tests $[9,10]$.

The study described in this paper was centred on investigating the performance of a range of floor coverings for in-room impact reduction, using impactors of different hardness, mass, impact velocity and geometry. The study included both an experimental investigation and a theoretical analysis based on the method of transfer path analysis (a method that is widely used in the automotive industry to investigate structure borne noise problems in vehicles). The purpose of the paper is to report the findings of these investigations in relation to how the rank order of performance of floor coverings varies depending on the method of excitation and the means of measurement. The intention of the paper is not to propose a new standard procedure for the measurement of in room impact noise but the findings do highlight some important test requirements as well as the advantages and disadvantages with the methods investigated which may be useful for future optimised standard developments. 


\section{Background}

The two most dominant mechanisms of impact noise are referred to as acceleration and ringing noise, and in some cases air ejection noise can also contribute. Acceleration noise is defined by Richards et al [11] as "that which is caused by the rapid acceleration or deceleration of the parts of the machine, or a change in shape of the workpiece", and in the context of in room impact noise this might be considered as:

- A combination of the initial pulse of sound that is radiated directly by the impacting object as it is rapidly decelerated by the floor; and

- The initial pulse of sound that is radiated by the floor, and/or floor covering, due to its rapid deformation around the impact point.

Ringing noise, on the other hand, is defined in [12] by Richards as "the longer term vibratory motion of the machine or workpiece as it dissipates its vibration energy as noise or heat", which can be expected to occur in both the floor and the impacting object itself post impact. To most, the term ringing noise should be quite familiar, but the same cannot be said of acceleration noise, which is somewhat more abstract as a concept.

The most simply understood manifestation of what Richards refers to as acceleration noise [11] is a "change in shape of the workpiece" because it is clear that a hard object striking a soft floor may cause a sudden indentation of the surface resulting in a pressure fluctuation. Less easily visualized however is the acceleration noise that is known to occur when a rigid object is rapidly decelerated because, in this manifestation, the impacting object need not deform at all. Instead, the mechanism for noise generation here is the air that is being naturally displaced/entrained by the impactor being reflecting from its surface when it is brought to a stop.

For the simple case of a spherical impactor [11] (and assuming short impact duration) the acceleration sound energy $E_{A c c}$ can be approximated by,

$$
E_{\text {Acc }}=\frac{1}{3} \pi r^{3} \rho_{0} v_{0}^{2}
$$

Where $r$ is the radius of the sphere, $\rho_{0}$ is the density of air, and $v_{0}$ is the velocity on impact. This radiated sound energy is referred to in [11] as being, "equal to half the kinetic energy of an air bag of the same fluid volume as the sphere travelling at the same impact velocity". From this, it can be understood that the radiated sound energy is related to the size of the impactor and its velocity at the point of impact and that there is a stronger dependence on the radius of the sphere than the impact velocity (larger objects and higher impact velocities produce more "acceleration" sound energy). However, since the size and impact velocity of an object cannot be controlled in any way by a floor covering, it is instead the impact duration [9] (which relates to both acceleration and force) that is of most interest in terms of in-room impact noise reduction. 
A resilient floor covering can be modelled by first approximation as an idealized spring, of stiffness $k$, terminated by an immovable object [13]. In this case, a perfectly rigid impacting object, of mass $\mathrm{m}$, would have an impact duration T of,

$$
T=\pi \sqrt{\frac{m}{k}}
$$

If, however, the face of the impactor is not stiff relative to that of the floor covering, the stiffness of the impactor should also be taken into account and the stiffness term, $k$, in equation (2) should be replaced by,

$$
k=\left(\frac{1}{k_{1}}+\frac{1}{k_{2}}\right)^{-1}
$$

where $k_{1}$ is the stiffness of the impactor and $k_{2}$ is the stiffness of the floor covering. Equations (2) and (3) clearly show that the duration of the impact depends on the contact stiffness, and that this contact stiffness is governed by whichever surface is least stiff. Soft floor coverings can therefore be expected to extend the impact duration (thereby reducing peak impact force, acceleration and noise) but only significantly when the floor covering is soft relative to the impactor. The impact noise reduction provided by a soft floor covering will therefore be most significant for hard impacting objects.

A further important consequence of extended impact duration is the frequency content of the excitation. This can be demonstrated using the Fourier spectrum (frequency representation) of a half sine force pulse, $F(f)$, which can be written as,

$$
F(f)=2 F_{\text {peak }} \frac{T}{\pi}\left|\frac{\cos (\pi f T)}{1-(2 f T)^{2}}\right|
$$

where $F_{\text {peak }}$ is the peak force amplitude in the time domain, $\mathrm{f}$ is frequency and $\mathrm{T}$ is the impact duration $[9,14]$. Shown in Figure 1 is such a frequency spectrum for a half sine pulse of $1 \mathrm{~N}$ peak force and a duration T of 0.01 seconds. It can be seen that the force spectrum is a flat line until approximately $1000 \mathrm{~Hz}$ where the magnitude of the force starts to roll off, which occurs at the cut off frequency, $f_{c}$. Thus the longer the impact duration, the lower the cut off frequency, and this means a reduction in the impact force at high frequencies. This is of importance to impact noise because human hearing is less sensitive at low frequencies, and objects dropped onto soft surfaces will therefore be perceived as being less loud as a result. 


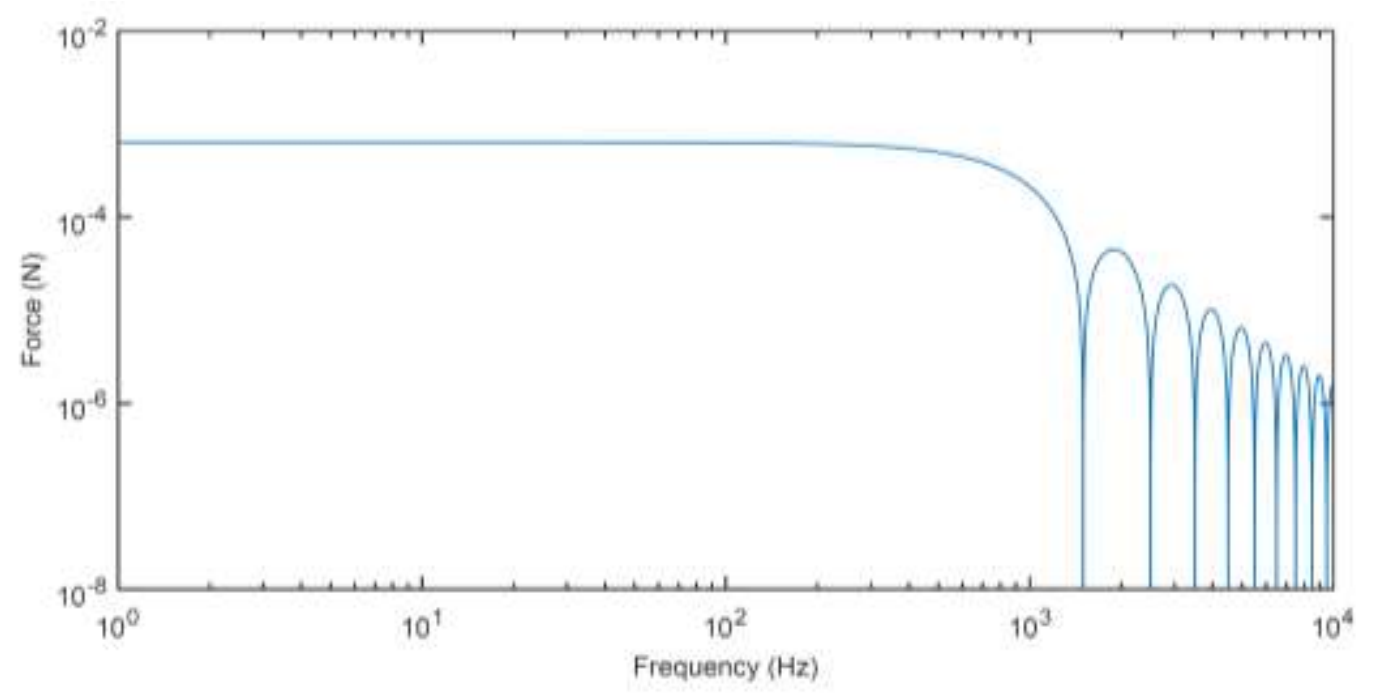

Figure 1: Frequency spectrum of a half sine force pulse of impact duration 0.01 seconds and a peak force amplitude of $1 \mathbf{N}$.

It should be noted that the physical mechanisms governing impact duration are considerably more complex than described above, see e.g. [15], because the stiffness of a floor covering is likely to vary non-linearly with respect to impact load, and will depend on the geometry of the impactor. Furthermore, most falling objects will bounce, resulting in subsequent impact sounds of a lower sound level. This may not significantly affect the overall sound level, but it does perhaps have implications for sound quality and annoyance. Considering all these factors, it is clearly not straightforward to devise a simple test that comprehensively covers all falling objects, floor coverings and floor types and, furthermore, the most appropriate acoustic metric to use is not necessarily obvious either. The following section describing a transfer path analysis of a falling object is provided to illustrate the factors influencing in room impact noise and the dependencies relating to its control by a floor covering.

\section{Theory: Transfer Path Analysis}

On impact, the force applied to a falling object is equal to the force applied to the floor where it is struck. A consequence of this is that the noise from the impactor and the noise from the floor must both reduced by the same amount when a floor covering is present because,

$$
P_{\text {total }}=\left(H_{\text {floor }}+H_{\text {object }}\right) F
$$

where $\mathrm{P}_{\text {total }}$ is the total radiated noise, $\mathrm{F}$ is the impact force, and $\mathrm{H}_{\text {floor }}, \mathrm{H}_{\text {object }}$ are the amount of sound radiated by the floor (including floor covering) and the object respectively per unit force input, neither of which is significantly altered by most thin floor coverings. Note that $\mathrm{H}_{\text {floor }}$ and $\mathrm{H}_{\text {object }}$ may each have component 
contributions resulting from both acceleration and ringing noise, but air ejection noise would not be accounted for in this formulation. Thus, assuming air ejection noise is negligible, we may also write,

$$
\begin{gathered}
P_{\text {floor }}=H_{\text {floor }} F \\
P_{\text {object }}=H_{\text {object }} F
\end{gathered}
$$

and the remaining problem is then to determine the force of the impact which can be done by inverse force synthesis [16] (as used in transfer path analysis [17]) using the equation,

$$
F=\frac{a_{\text {floor }}}{A_{\text {floor }}}
$$

where $a_{\text {floor }}$ is the acceleration of the floor, which can be measured by accelerometer, and $A_{\text {floor }}$ is the accelerance of the floor, which can be obtained by measuring the acceleration of the floor when excited by an instrumented hammer. Similarly, the vibro-acoustic frequency response functions $H_{\text {floor }}$ and $H_{\text {object }}$ can be measured by exciting the floor and the object with an instrumented hammer whilst measuring the resulting sound pressure. Equations (6) to (8) therefore allow us to separate out the contributions of the floor and the object, as will be shown in the following section.

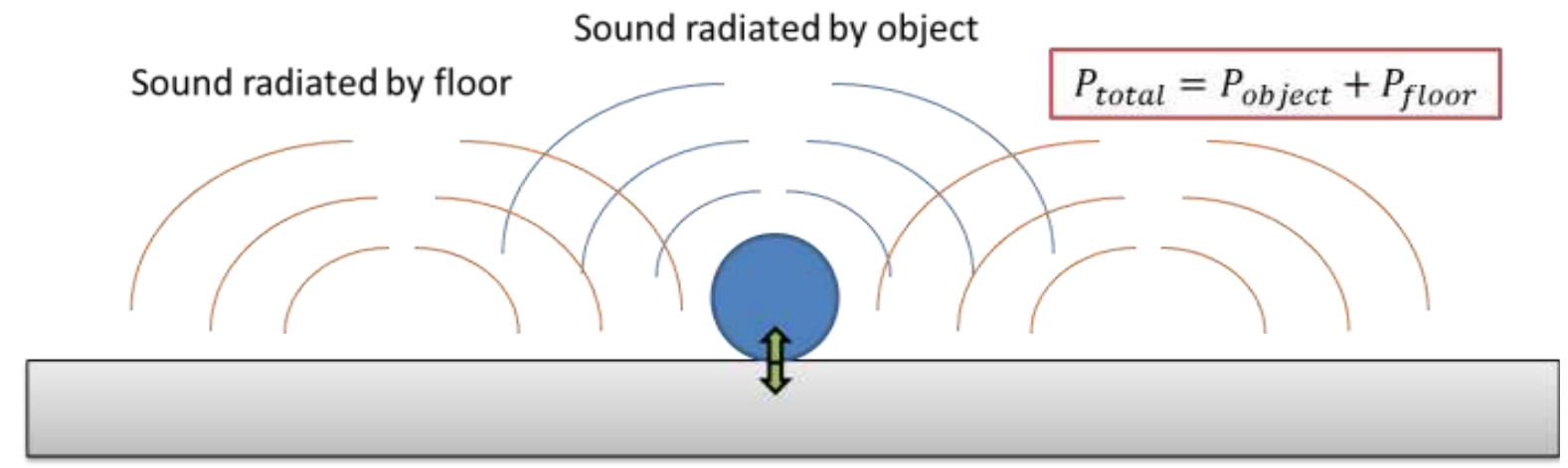

Figure 2: In-room impact noise includes a contribution from the falling object as well as from the floor.

What is particularly interesting about equations (5) to (7) is that $H_{\text {floor }}$ and $H_{\text {object }}$ are constants, which means the floor can only affect the sound pressure by changing the frequency spectrum of the force. It is possible of course that $H_{\text {floor }}$ may vary from one floor covering to another, but this could be less than one might expect, especially for rubber floor coverings that provide little in the way of sound absorption or sound insulation. However, this may not be the case for all types of floor coverings, with laminate floor coverings, which are non- 
locally reacting, being an exception. The Implication of this is, that for locally reacting floor coverings, the impact force alone could be the most transparent indicator of in room impact noise reduction.

It is also interesting to note that because $H_{\text {floor }}$ includes both acceleration and ringing noise, both radiation mechanisms will be affected equally, and the most significant effect the floor covering can have in terms of impact noise reduction is therefore to modify the force. This is assuming the floor covering does not significantly damp the vibration of the object (ringing noise), which is unlikely to be the case in most instances because the impacting object generally bounces and is airborne (undamped) following an impact until it comes to rest.

It is also interesting to note that depending on the falling object, the floor covering and the building structure the contribution of the object and the floor to ptotal will vary and that either one or the other may dominate, or similarly they may equivalent in level. When the floor dominates $P_{\text {total }} \approx H_{\text {floor }} F$, and when the falling object dominates $P_{\text {total }} \approx H_{\text {object }} F$; when they are at a similar level $P_{\text {total }}=\left(H_{\text {floor }}+H_{\text {object }}\right) F$. Thus, If we define the impact noise reduction as $\Delta P_{\text {total }}=20 \log _{10}\left(p_{\text {total }}^{\prime} / p_{\text {total }}\right)$, where dash denotes the bare floor without the floor covering, there are three possible scenarios,

$$
\begin{gathered}
\Delta P_{\text {total }}=20 \log _{10}\left[\frac{\left(H_{\text {floor }}^{\prime}+H_{\text {object }}\right) F^{\prime}}{\left(H_{\text {floor }}+H_{\text {object }}\right) F}\right](d B) \\
\Delta P_{\text {total }} \approx 20 \log _{10}\left[\frac{H_{\text {floor }}^{\prime} F^{\prime}}{H_{\text {floor }} F}\right](d B) \\
\Delta P_{\text {total }} \approx 20 \log _{10}\left[\frac{F^{\prime}}{F}\right](d B)
\end{gathered}
$$

where equations (9), (10) and (11) correspond to the cases where neither the floor nor the object dominates, where the floor dominates and where the falling object dominates respectively. From equation (9) it is clear that when neither floor nor object dominates, there can be no one general solution to $\Delta P_{\text {total }}$ that applies to all objects and floors. Similarly, for equation (10), there is again no general solution because the FRF of the bare and covered floors could potentially vary for some floor coverings, as well as the force spectrum. If the FRF of the covered and uncovered floor are the same however, or if the sound from the falling object dominates, we then have the case described by equation (11). In this case $\Delta P_{\text {total }}$ then depends only on how the force of the impact is modified by the floor covering. Equation (11) is still not a general solution however, even for these specific cases, because the ratio $F^{\prime} / F$ is unfortunately not a constant for all impactor types, due to non-linearity and varying contact mechanics (see equations (3) and (4) for example). This is especially true if the desire is to provide a single number rating that is related to human perceptions of loudness because when A-weighted, for example, the force spectra of the bare and uncovered floors will peak at different frequencies depending on the properties of the impacting object. In the following section a transfer path analysis of a falling object is 
demonstrated, and in the subsequent section the issue of varying impact noise reductions for different impacting objects is addressed by a survey which included several impactor types with varying mass, stiffness and impact velocities.

\section{Experimental Study: Impact Noise Transfer Path Analysis}

In order to demonstrate the application of equations (6) to (8) in performing an impact noise transfer path analysis, an experiment was set up in a semi-anechoic chamber as shown in Figure 3. The experiment consisted of a tripod with a fluorocarbon solid synthetic fluoropolymer (PTFE) bearing supporting a further PTFE rod (sliding within) to which different impactors could be attached. The impacting objects considered included a hollow steel ball, a table leg and a book. For the illustration of the impact noise transfer path analysis, we focus on data obtained from a short section of a chair leg, which exhibits a combination of acceleration noise and ringing noise in the frequency range of interest.

A small concrete block was used to represent a hard floor under the floor coverings $(14.5 \mathrm{~cm} \times 14.5 \mathrm{~cm} \times 14.5 \mathrm{~cm}$ with a mass of $16.4 \mathrm{~kg}$ ). This block was isolated from the laboratory floor using a thin layer of foam, and was instrumented with 4 accelerometers mounted in the vertical direction at the centre of the four vertical faces of the cube. Microphones were set up in the arrangement required to determine the sound power according to ISO3744:2010 [18] and data was logged synchronously for all microphones, accelerometers and the hammer.

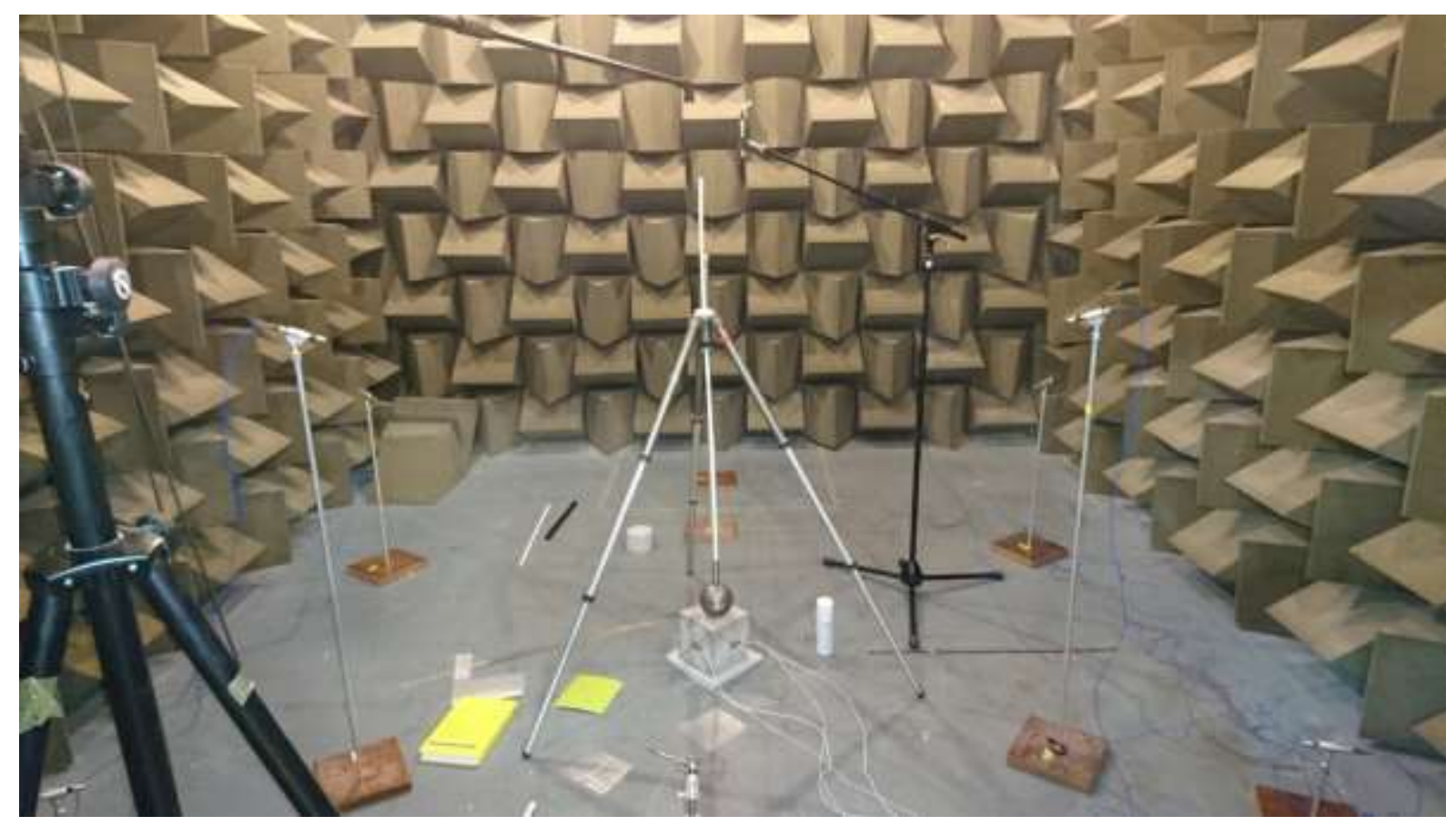

Figure 3: Experimental test setup employed in the semi-anechoic chamber. 
An instrumented hammer was used to measure frequency response functions relating impact force to the acceleration of the block Afloor, and to measure the vibro-acoustic frequency response functions ( $\mathrm{H}_{\text {floor }}$ and $\mathrm{H}_{\text {object }}$ ). In order to estimate the force on the block due to each impact, the measured accelerance and acceleration of the block was used along with equation (8) which, when combined with a measure of the frequency response function relating sound pressure to force, could be used to estimate the sound pressure directly radiated by the impactor alone using equation (7). The same procedure was also carried out to estimate the sound radiated directly by the block with/without floor coverings so that the relative contributions, block or impactor, could be compared. This approach, known as transfer path analysis, has been used for the investigation of structure borne noise for several years, but until now has not been applied to in-room impact noise. Some uncertainty can therefore be expected due to the infancy of the technique for this application, and also because when the vibro-acoustic frequency response functions of the impactors were measured they were freely suspended and un-damped. In practice, on impact, a falling object would make an intermittent contact with the floor, which is likely to result in some damping that could reduce ringing noise, albeit only briefly. For this reason, estimates of ringing noise might be expected to be higher than what is actually observed in practice.

Shown in Figure 4 is the total sound pressure in Pascal plotted in a narrow band frequency resolution; the black line is the total sound pressure measured at one of the microphone positions and the blue line is calculated using equation (7) for the impactor. The lower plot in Figure 4 compares the total noise to that which is estimated to be radiated from the block and the floor covering only (red line) using equation (6). In this case, there is a combination of ringing noise from the impactor and acceleration noise from the floor/impactor that contribute to the total noise, which dominates overall when A-weighted as shown in Figure 5 . It can also be seen in Figure 4 that in general the level of the ringing noise is predicted reasonably well using equation (7), with the exception of the first resonance of the chair leg which is overestimated. This is likely due to the floor covering damping, or not exciting fully, the first mode of chair leg.

Considering the possibility of alternative test methods, it is interesting to note that the reduction in impact noise due to ringing of the object is governed predominantly by the change in the impact force. This can be seen from equation (7) where the force depends on the floor covering, whereas the vibro-acoustic frequency response function of the object depends only on the object itself. Thus, the reduction in ringing noise for a given object is governed by the floor covering's effect on impact force. The reduction of impact force could therefore potentially be used as an indicator of actual floor covering performance. In practice, this could be a more transparent indicator than radiated sound because it would be less object specific, although that is not true entirely, as will be demonstrated in the following section where several different impactors are employed.

During these test, 10 floor coverings (see table 1 in the following section) were investigated. Shown in Figure 5 are the corresponding one third octave band energy spectra for each of them and the bare floor (black line) for the example of a ringing chair leg impactor. Below $1000 \mathrm{~Hz}$ the spectrum appears to be dominated by acceleration noise, but above this frequency ringing of the chair leg became increasingly dominant. This therefore serves to illustrate the mechanisms by which differing in room impact noise reductions may be 
observed for a given floor covering when different impactor types are used. This is especially true when the data is A-weighted a the frequency spectrum is widely varying with frequency as is likely to be the case when ringing noise is present (see Figure 4).
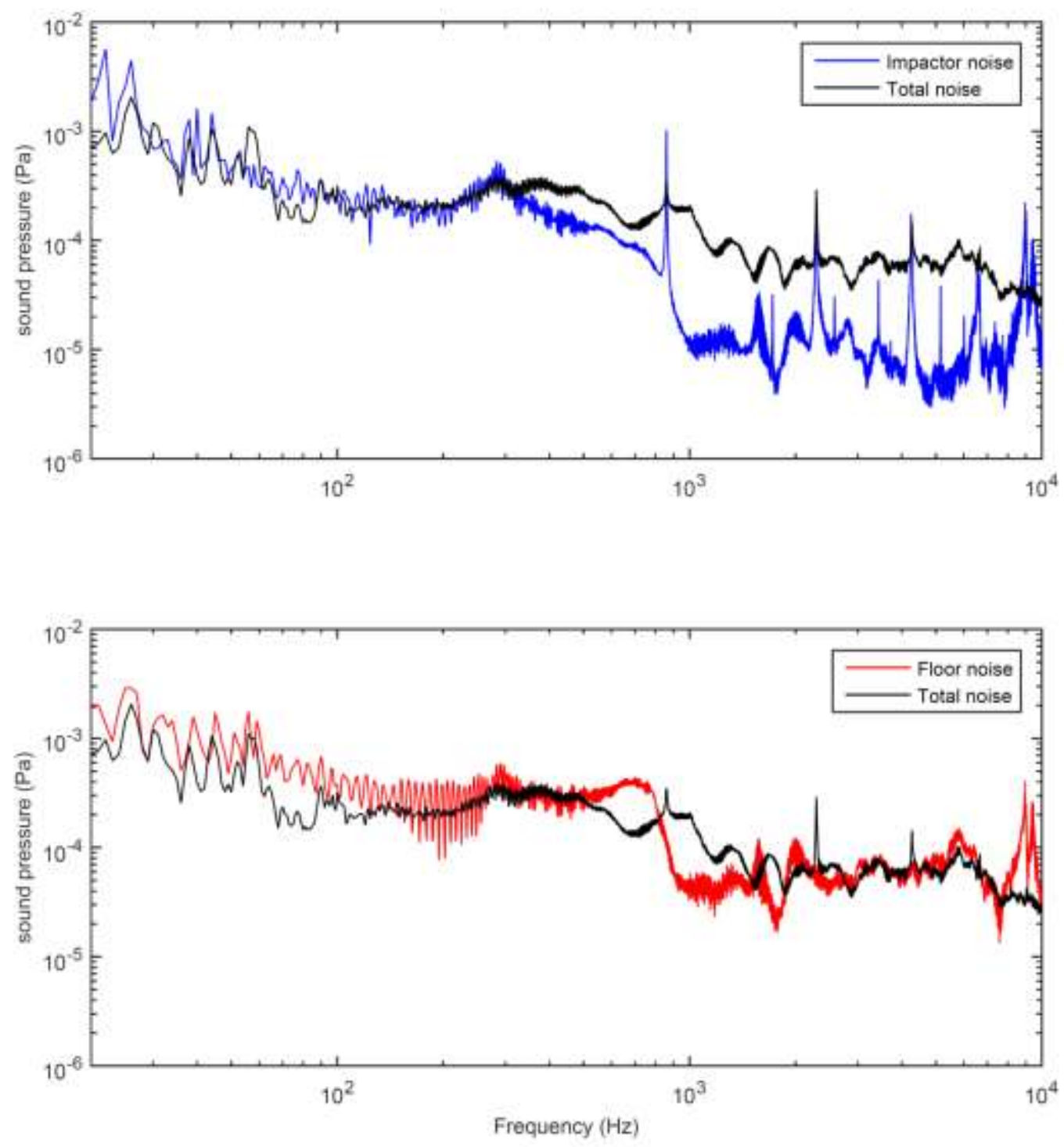

Figure 4: Top plot - Average sound pressure in Pascal versus frequency in narrow band showing total measured noise and the estimated noise from the impactor alone. Bottom plot - Comparison of total measured noise to the estimated noise from the block and floor covering. 


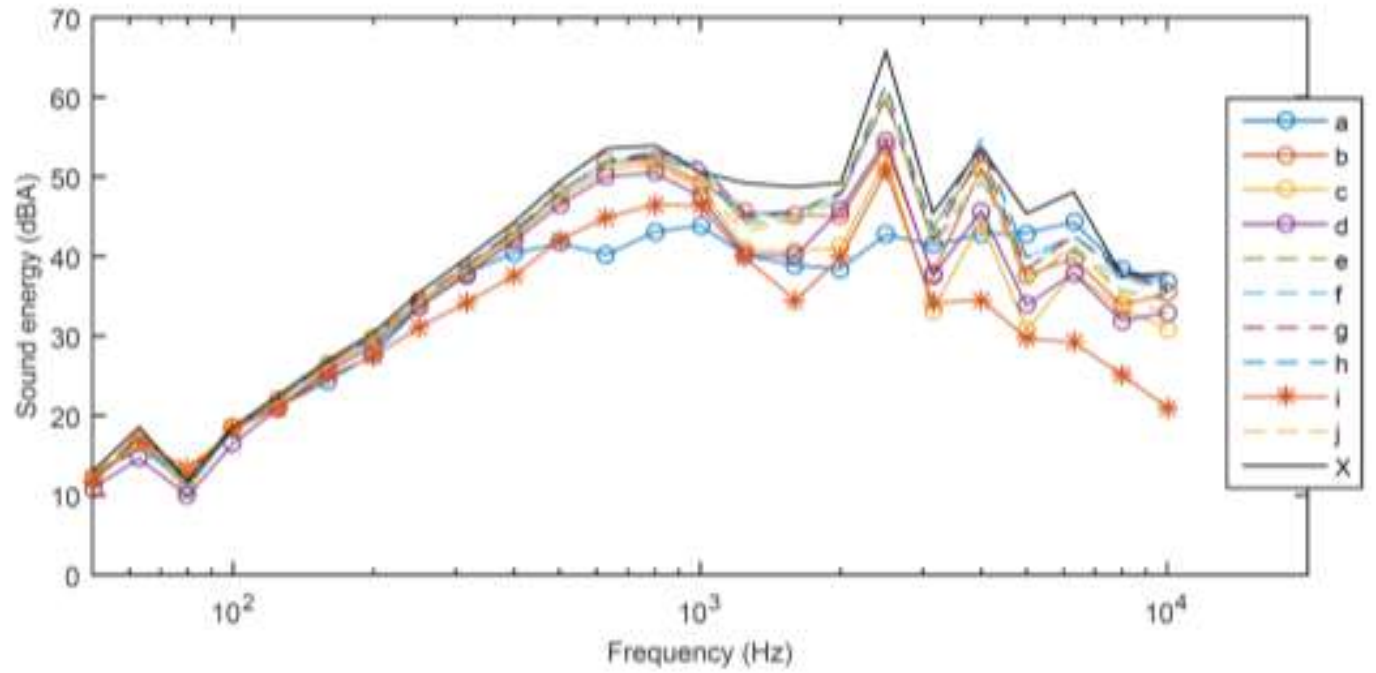

Figure 5: One-third-octave band sound energy spectrum for a ringing chair leg impactor on small $14.5 \times 14.5 \mathrm{~cm}$ samples of floor coverings applied to a solid concrete block. 


\section{Experimental Study: Impact noise reduction}

The University of Salford's large reverberation chamber (volume $220 \mathrm{~m}^{3}$ ) was instrumented with six microphones, and placed close to the centre of the reverberation chamber was a raised concrete slab $(1.5 \mathrm{~m} \mathrm{x}$ $1.5 \mathrm{~m} \times 0.1 \mathrm{~m})$. The slab itself was mounted on four rubber vibration isolators to reduce vibration transmission to the reverberation chamber floor, and the floor was instrumented with 5 accelerometers (one in each corner and one situated midway along one edge). It was then shuttered around its edge using plasterboard and mineral wool to reduce sound transmission from its underside as shown in Figure 6. Shown in Figure 7 is the experimental test setup used. The size of the concrete slab used for the tests was chosen based on the size of the entrance to the reverberation chamber, i.e. it was the largest floor area which could be brought in and out of the chamber safely. A larger slab more representative a real building would have been preferable, but much larger floor covering samples would then also have been required.

The aim of the impact testing described in this section of the paper was to determine the A-weighted impact sound energy level for each floor covering for comparison with that of the bare concrete floor (the reference). The 10 floor covering samples in Table 1 below were used in investigation.

\begin{tabular}{|l|l|l|}
\hline Sample ref & Type & Thickness \\
\hline A & Rubber & $4 \mathrm{~mm}$ \\
\hline B & Rubber & $3 \mathrm{~mm}$ \\
\hline C & Rubber & $2 \mathrm{~mm}$ \\
\hline D & Rubber & $3.5 \mathrm{~mm}$ \\
\hline E & $\begin{array}{l}\text { Homogeneous PVC-Free Sheet with PUR } \\
\text { Factory Applied Topcoat }\end{array}$ & $2 \mathrm{~mm}$ \\
\hline F & Linoleum & $2.5 \mathrm{~mm}$ \\
\hline G & Homogeneous PVC Sheet & $2 \mathrm{~mm}$ \\
\hline H & VCT (Vinyl Composition Tile) & $3.2 \mathrm{~mm}$ \\
\hline I & Carpet & $6.5 \mathrm{~mm}$ \\
\hline J & LVT (Luxury Vinyl Tile) & $2 \mathrm{~mm}$ \\
\hline X & Bare concrete floor 1.5 $\times 1.5 \times 0.1 \mathrm{~m}$ & $\mathrm{~N} / \mathrm{A}$ \\
\hline
\end{tabular}

Table 1: Floor covering types tested - the first column of the table gives the single letter references which shall be used throughout to refer to the floor materials. 
All floor coverings were attached to the floor using an adhesive sheet with no resilient layer between the floor coverings and the bare concrete floor. The insertion loss, IL, in each case was calculated from the overall Aweighted sound levels using equation (12). The A-weighted insertion loss, $I L_{A}$, was given by

$$
I L_{A}=L_{W A, \text { bare }}-L_{W A, \text { covered }}
$$

where $L_{W A \text {,covered }}$ and $L_{W A \text {,bare }}$ are the overall, or total, A-weighted sound energy levels measured with and without the floor coverings applied respectively.

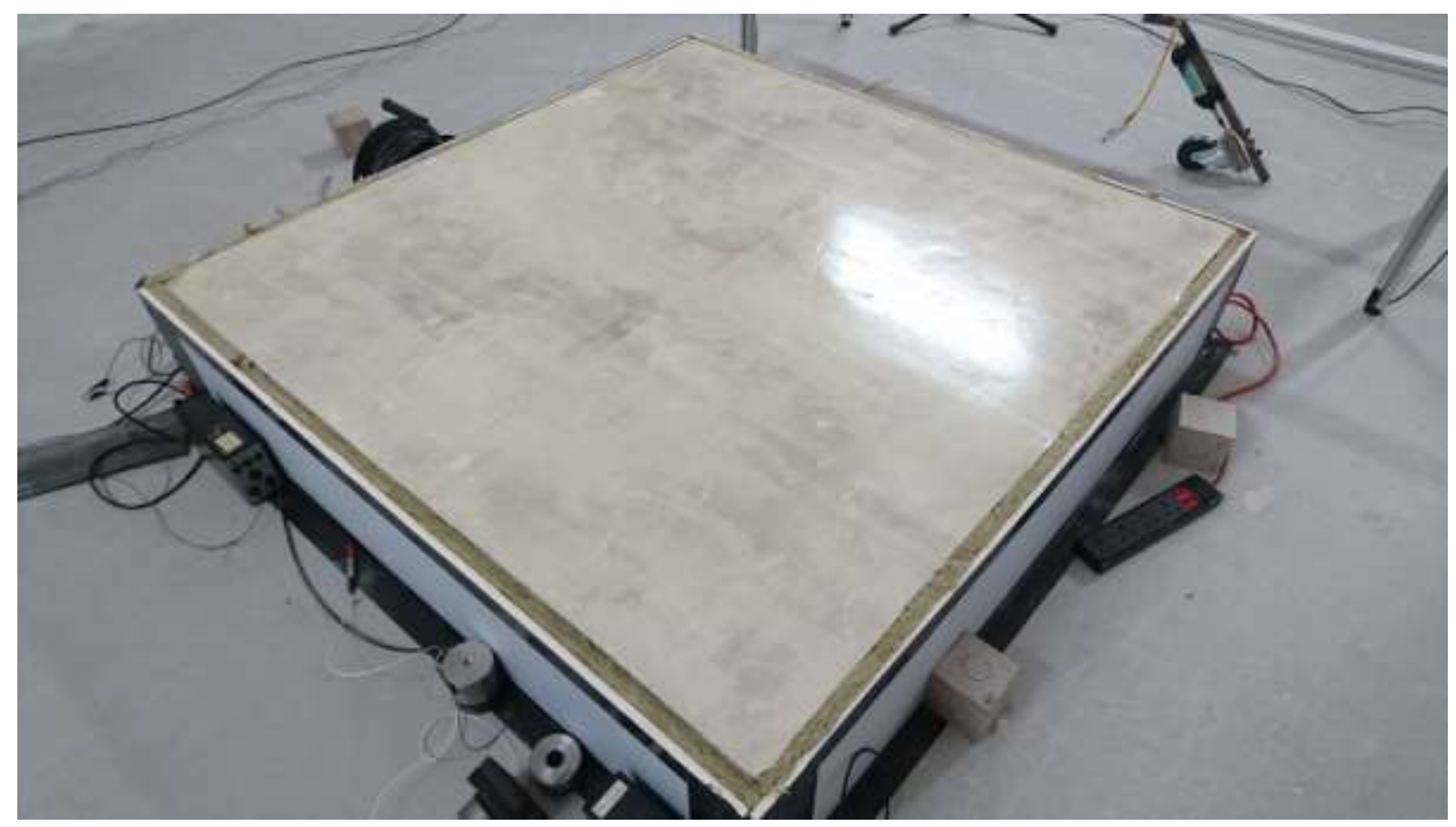

Figure 6: $1.5 \mathrm{~m} \times 1.5 \mathrm{~m} \times 0,1 \mathrm{~m}$ concrete slab with shuttering to reduce sound transmission from the underside of the floor. Also visible is the adhesive sheet which was used to bond the floor samples to the concrete.

The impact test assembly consisted of small and large impactor heads coupled to vertically mounted PTFE rods, which ran freely in PTFE linear bearings. Raising the impactors for each drop was done manually by wire. Large and small impactors were both employed and both were instrumented with force transducers with interchangeable tips allowing the hardness of the impacting faces to be varied. Both impactors were also instrumented with accelerometers to measure the rate of acceleration on impact. 


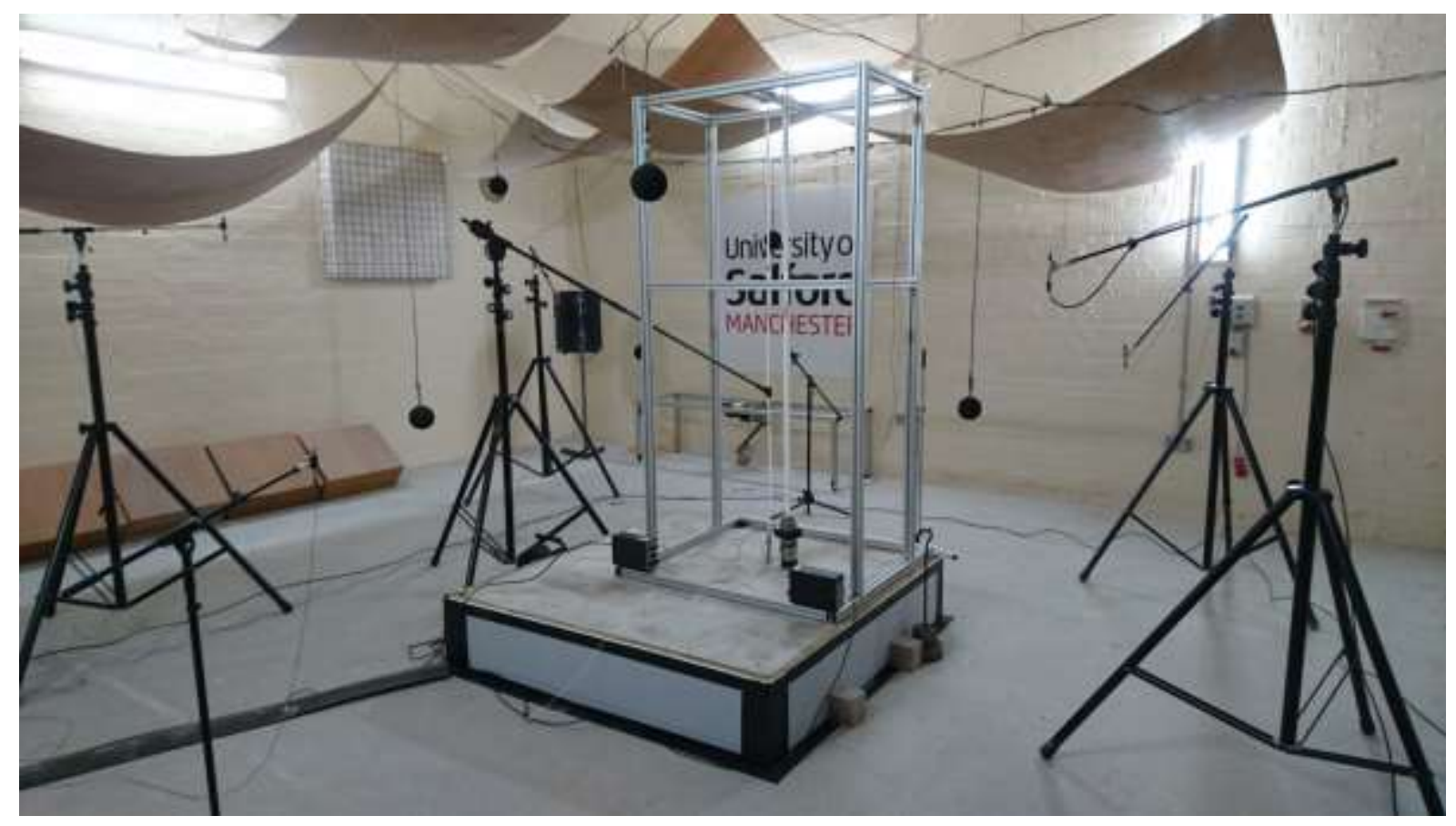

Figure 7: Drop test assembly on the bare concrete floor in the reverberation chamber.

The large impactor consisted of a large force transducer $(1.775 \mathrm{~kg})$ with two metal rings separated from each other, and from the force transducer, by foam; their masses were $0.959 \mathrm{~kg}$ and $1.509 \mathrm{~kg}$, see Figure 9 . The purpose of the resiliently mounted rings was to add mass and to prevent the impactor from bouncing, so as to better represent human footfall. Steel as well as soft and hard Urethane hammer tips were employed, with the former having a mass of $0.8 \mathrm{~kg}$ and the latter two $0.27 \mathrm{~kg}$, with the PTFE rod weighing $2.26 \mathrm{~kg}$. The overall weight of the large impactor was therefore $6.5 \mathrm{~kg}$, plus the mass of the tip used. All of the hammer tips used with this impactor had gently curved faces to ensure a repeatable point of impact.

Shown in Figure 8 are force time histories for the three different impactor faces resulting from single impacts on the bare floor. The hard and soft urethane impactor faces gave impact force time histories similar to the ground reaction forces associated with walking. The impact duration for the steel face was however much shorter in duration and less representative of walking forces at the heel. This impactor was included in the study to serve as a most severe case because it was anticipated that the biggest improvements in impact noise reduction would be observed with hard impactors. A $10 \mathrm{~cm}$ drop height was used for all impacts with this heavy impactor and all excitations were applied consistently at the same point close to, but not at, the centre of the slab. The same location was used for all impacts, both with and without the floor coverings and only one impact location was used in order for more impactor type variations to be tested in the available laboratory time. 

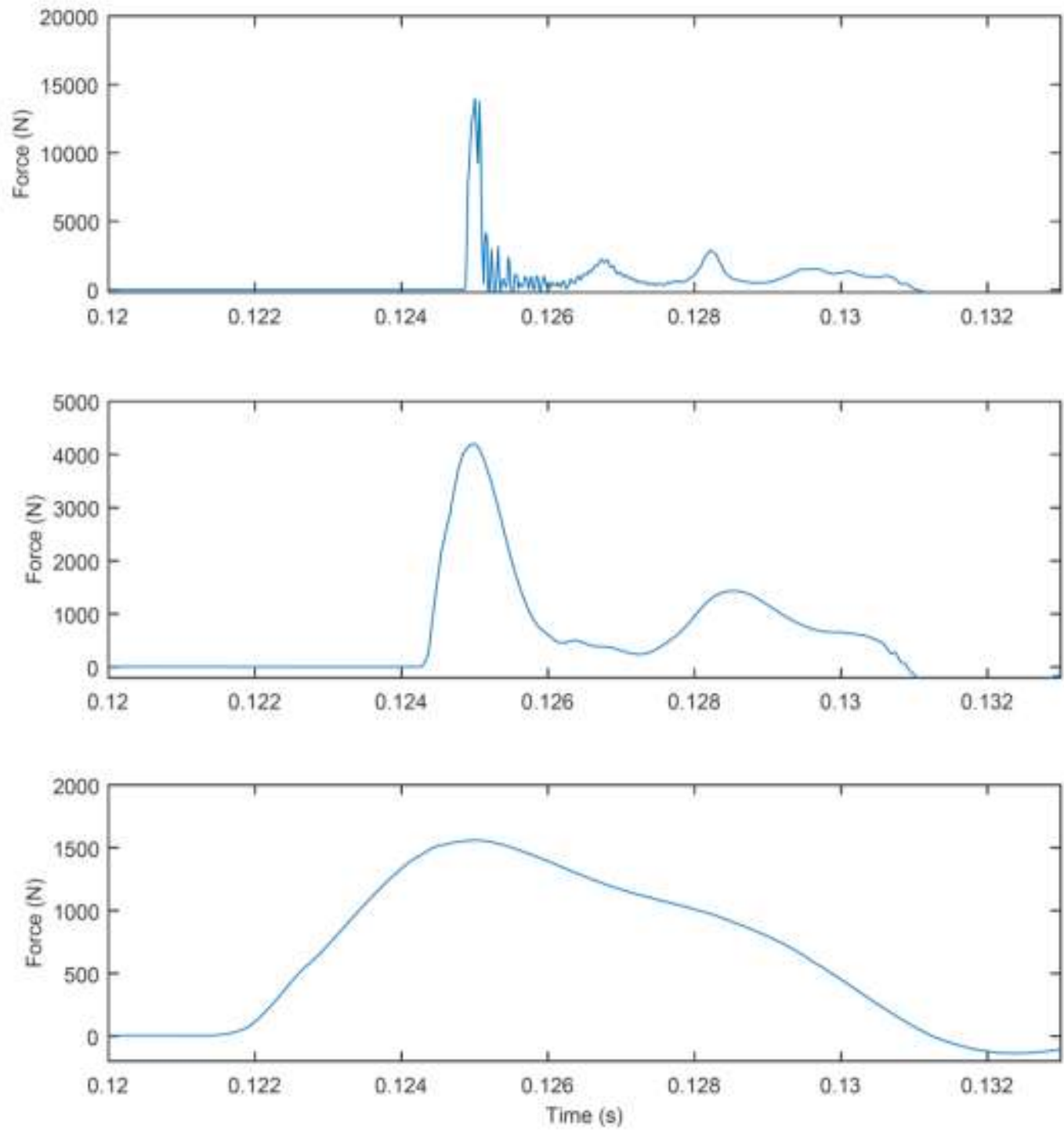

Figure 8: Force time histories for the steel, hard urethane and soft urethane impact faces; top, middle and bottom plots respectively (impacts on a hard floor). Drop height $10 \mathrm{~cm}$.

In addition to the heavy impactor, a smaller, lower mass impactor was also employed to represent smaller falling objects. This impactor, including the PTFE guide rod and force transducer with tip, weighed 470g. Again three tips were employed; steel, hard plastic and rubber. These hammer tips and the force transducer (B\&K type 8200) were from a Bruel and Kjaer force hammer type 8202 . A broader range of drop heights $(10 \mathrm{~cm}, 30 \mathrm{~cm}$ and $50 \mathrm{~cm}$ ) could be tested using this impactor without risk of damaging the floor: this allowed an investigation into whether the floor coverings behaved linearly. For tests with the smaller impactor, bouncing was permitted, as would be the case for real falling objects.

The sound energy of the impacts was calculated for each one third octave band according to, 


$$
L_{J}=L_{E(S T)}+\left[10 \lg \frac{A}{A_{0}}+4.34 \frac{A}{S}+10 \lg \left(1+\frac{S c}{8 V f}\right)+C_{1}+C_{2}+6\right](\mathrm{dB})
$$

where $L_{E(S T)}$ is the mean corrected- one third octave band- single event time-integrated sound pressure level in decibels [19]. $A$ is the equivalent absorption area, $A_{0}=1, S$ is the surface area of the reverberation chamber, $V$ is the volume of the chamber, $c$ is the speed of sound and $f$ is the third octave band centre frequency. $C_{1}$ and $C_{2}$ are small adjustments for air pressure and temperature that can generally be neglected. The reverberation time was measured with each floor covering in place to ensure that any changes in the sound absorption in the room could be taken into account through the equivalent absorption area term. With the exception of carpet, there was little variation in the reverberation time for the floor coverings tested. 


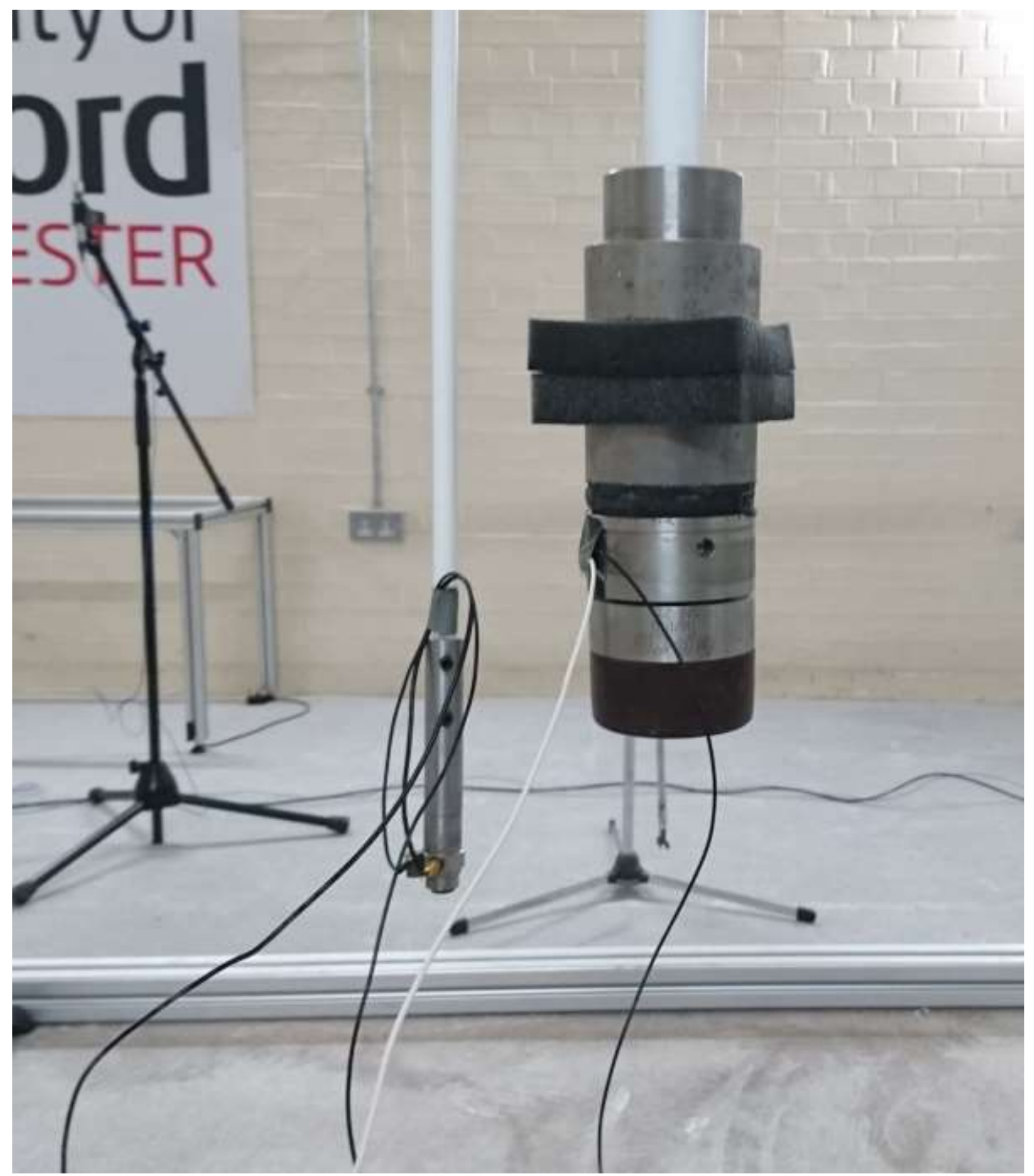

Figure 9: Photograph of the small and large instrumented impactors.

\section{Lightweight Impactor}

For the first insertion loss test, impacts were applied to the slab using the small impactor (employing three drop heights and varying impactor tip hardness'). The insertion loss of the 10 floor coverings was calculated using equations (12) and (13), and results are shown in Figure 10. Note that the connecting lines between the experimental points are only included only to make the plots easier to read and should not be used to interpolate between different drop heights. 
It can be seen in Figure 10 that the best performing floor covering for impact noise reduction was sample $\mathrm{A}$ ( $4 \mathrm{~mm}$ rubber) followed by sample I (carpet). Sample D (rubber $3.5 \mathrm{~mm}$ ) also stood out from the other products as being a good performer and B, C (rubber $2 / 3 \mathrm{~mm}$ ) were next best along with sample $\mathrm{E}$ ( $2 \mathrm{~mm}$ Homogeneous PVC-Free Sheet with PUR Factory Applied Topcoat). None of the floor coverings provided a greater sound reduction than $3 \mathrm{~dB}$ when the soft impact head was used.

It can also be observed that the softer floor coverings, which perform better for impact noise reduction, behaved less linearly, which can be seen as a gradual reduction in the sound insertion loss with drop height. This ought to be expected, because under higher loading the floor coverings will become compressed on impact, making them appear stiffer than is the case for lightweight impacts. Interestingly however, the rank order of the floor coverings does not appear to vary significantly for the different impact drop heights used, which implies that floor coverings that perform well for light impacts should also perform well for heavier impacts, even if their performance is somewhat reduced. Whether this applies to all floor coverings, and beyond the impact range covered, is not known however. 

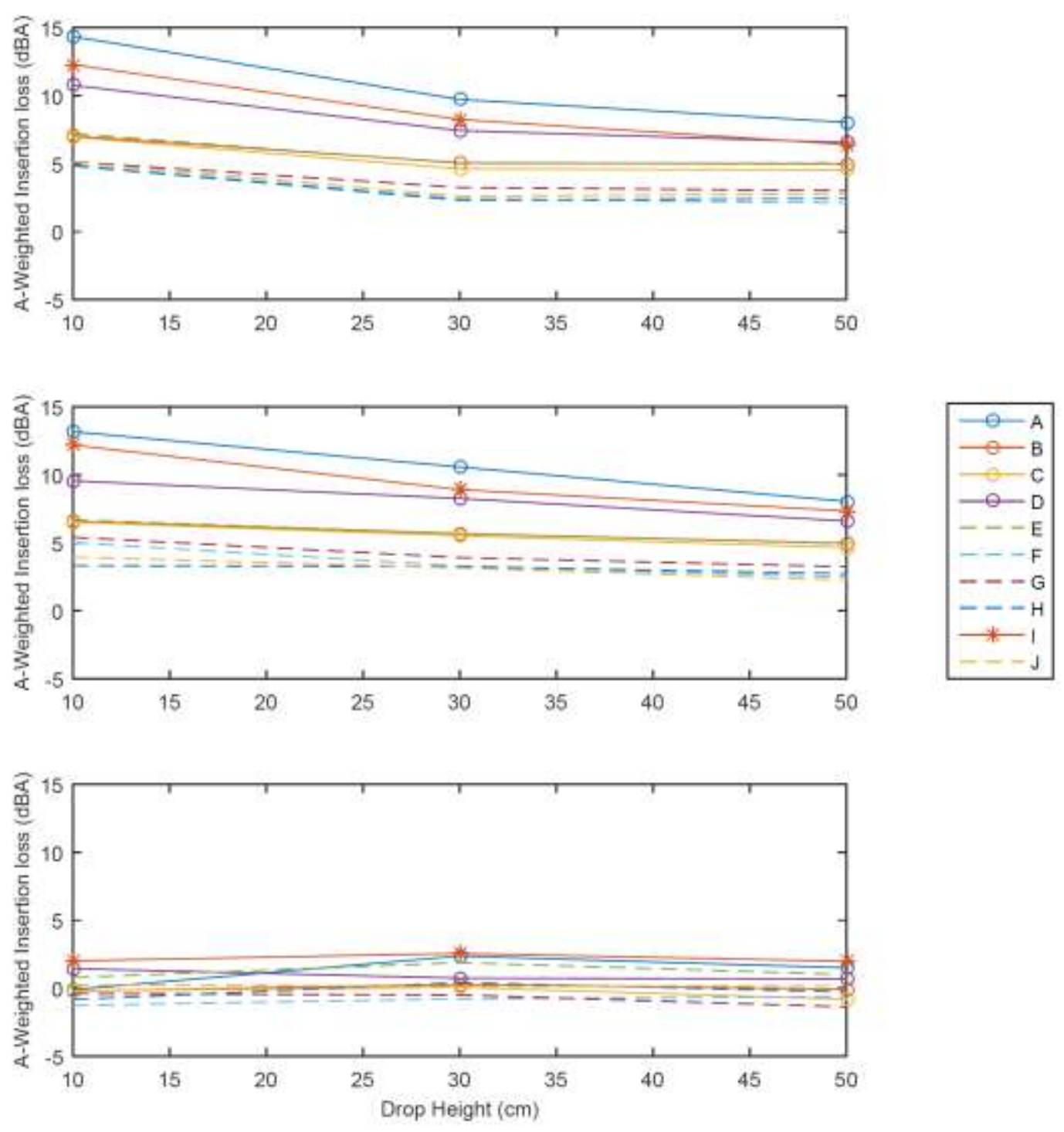

Figure 10: Insertion loss for three impactor drop heights $(10,30 \& 50 \mathrm{~cm})$. Top, middle and bottom plots correspond to steel, plastic and rubber hammer tips respectively.

Shown in Figure 11 are the one third octave band sound energy spectra from which the insertion loss results in Figure 10 were calculated. Results are plotted for the 10 floor coverings using the same markers and colour scheme as in Figure 10, with an additional black line giving results for the bare floor. This data was used to calculate the overall A-weighted sound energy levels, which were then used to obtain the single figure values shown in Figure 10 using equation (13). It can be seen in Figure 11 that none of the floor coverings are particularly effective below $300 \mathrm{~Hz}$, but all did provide some insertion loss above approximately $1000 \mathrm{~Hz}$. 

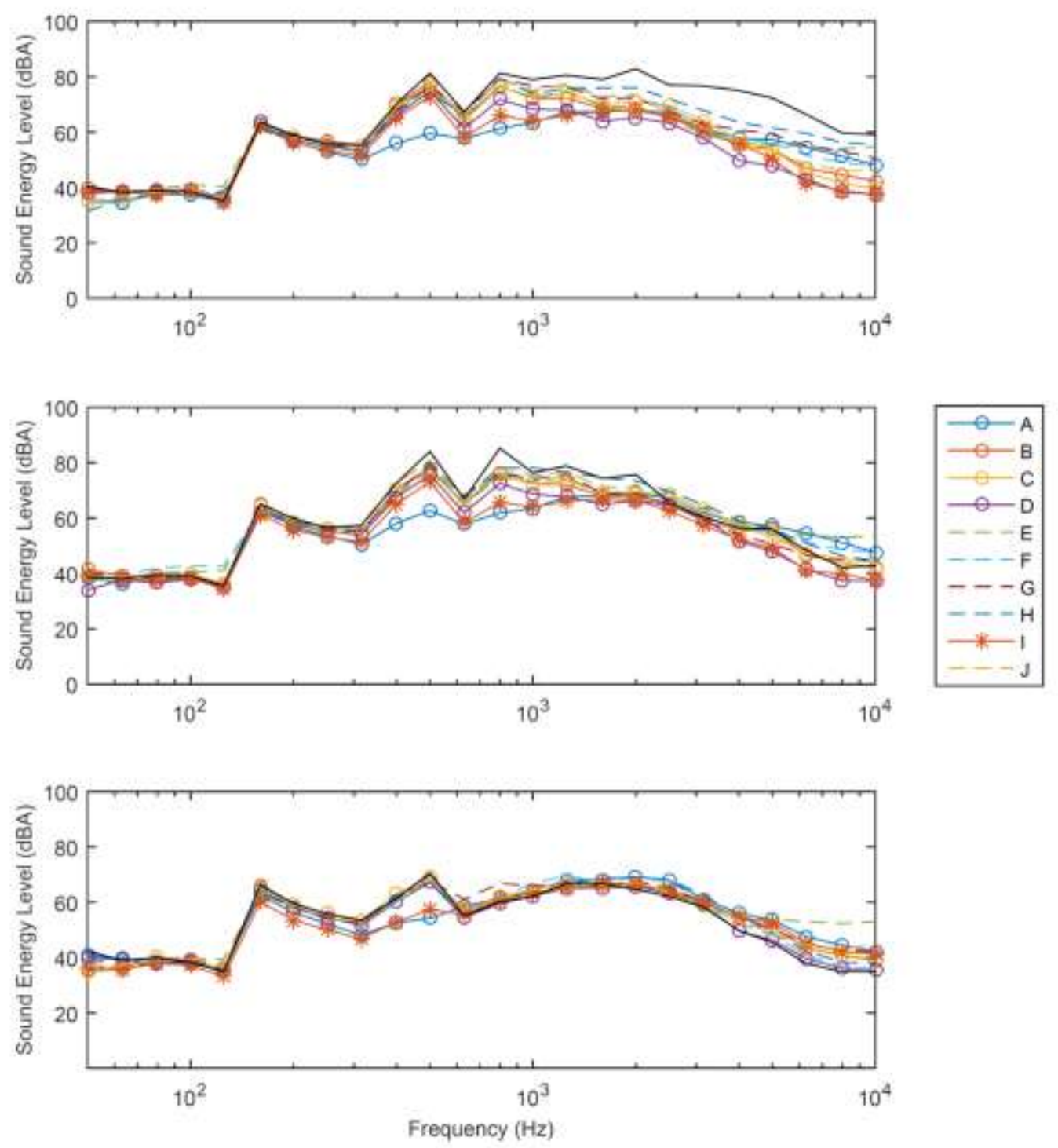

Figure 11: Sound energy for a $10 \mathrm{~cm}$ drop of the small instrumented impactor. The black solid line gives results for the bare floor. The top, middle and bottom plots correspond to the three impactor heads used; steel, plastic and rubber respectively.

Shown in Figure 12 are the measured impact forces in one third octave bands for the 10 floor samples and the bare floor (10cm drop). The highest performing floor coverings were found to correspond to those with the lowest force spectrum. This raises the possibility that measured force, rather than measured sound pressure, could be used to rate the sound impact reduction of locally reacting floor coverings. Such an alternative method would be appealing because it would avoid the requirement for a reverberant or anechoic test environment, and would also avoid uncertainties resulting from noise radiated by the drop test assembly itself. Similar arguments could also be made for using acceleration measurements on the slab, which showed similar 
trends in terms of the impact noise reduction. However, for the specific case of in room impact noise, it may not be that clear cut due to the several noise generation mechanisms that can contribute to the total noise.

One noise mechanism in particular that is of concern is acceleration noise in the form of deformation of the floor covering. For carpet and hard floor coverings this can be expected to be negligible, however for soft rubber or laminate floor coverings this noise generation mechanism could be significant, and unfortunately may not be detectable in the impact force or floor acceleration levels. In some instances, this mechanism could in fact increase in-room impact noise compared to the bare floor (at specific frequencies). This phenomenon could have a significant effect for some laminate floor coverings (i.e. floors or coverings that are not locally reacting) and this can be observed to some extent for sample A which is a foam backed rubber floor covering. This can be observed in the third-octave-band spectra for sample A in Figure 11 and Figure 12 in the high frequency range.

It is also interesting to note, from Figure 12, that the force of the impact is affected most significantly in the most sensitive range of human hearing by the softer floor coverings (as was confirmed by measurements of the A-weighted sound pressure level recorded at the same time as the impact force shown in Figure 11). Furthermore, the separation between the force spectra could potentially make differences in the impact force easier to resolve. 

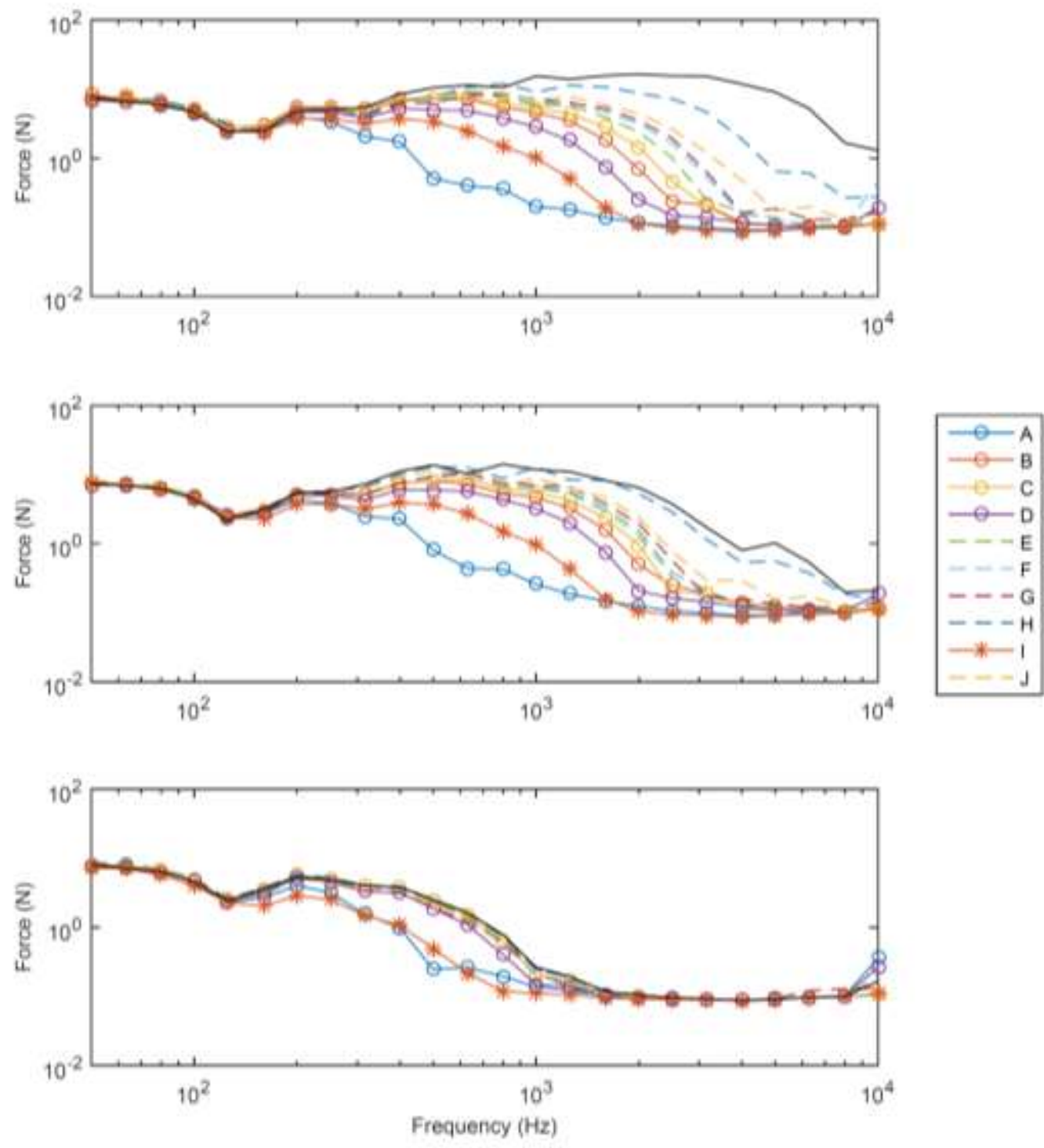

Figure 12: Measured force impact levels for a $10 \mathrm{~cm}$ drop of the small instrumented impactor. The top, middle and bottom plots correspond to the three impactor heads used; steel, plastic and rubber respectively. 


\section{Large impactor on $1.5 \mathrm{~m} \times 1.5 \mathrm{~m}$ concrete floor}

Continuiing with the same test methodology a larger impactor was used to test the same floor coverings (Table 1) which more closely approximated the loads associated with human footfall. Shown in Figure 13 are the impact sound energies in one third octave bands for the three impactor tips used; steel tip (top), medium hard urethane tip (middle) and soft urethane tip (bottom). Again, it can be observed that the floor coverings were more effective in reducing impact sound energy when the harder impactors were employed. Shown in Figure 14 are the corresponding insertion losses for the 10 floor coverings. Unlike Figure 10 this data is presented in the form of a bar plot as no variation drop height was investigated for this impactor.
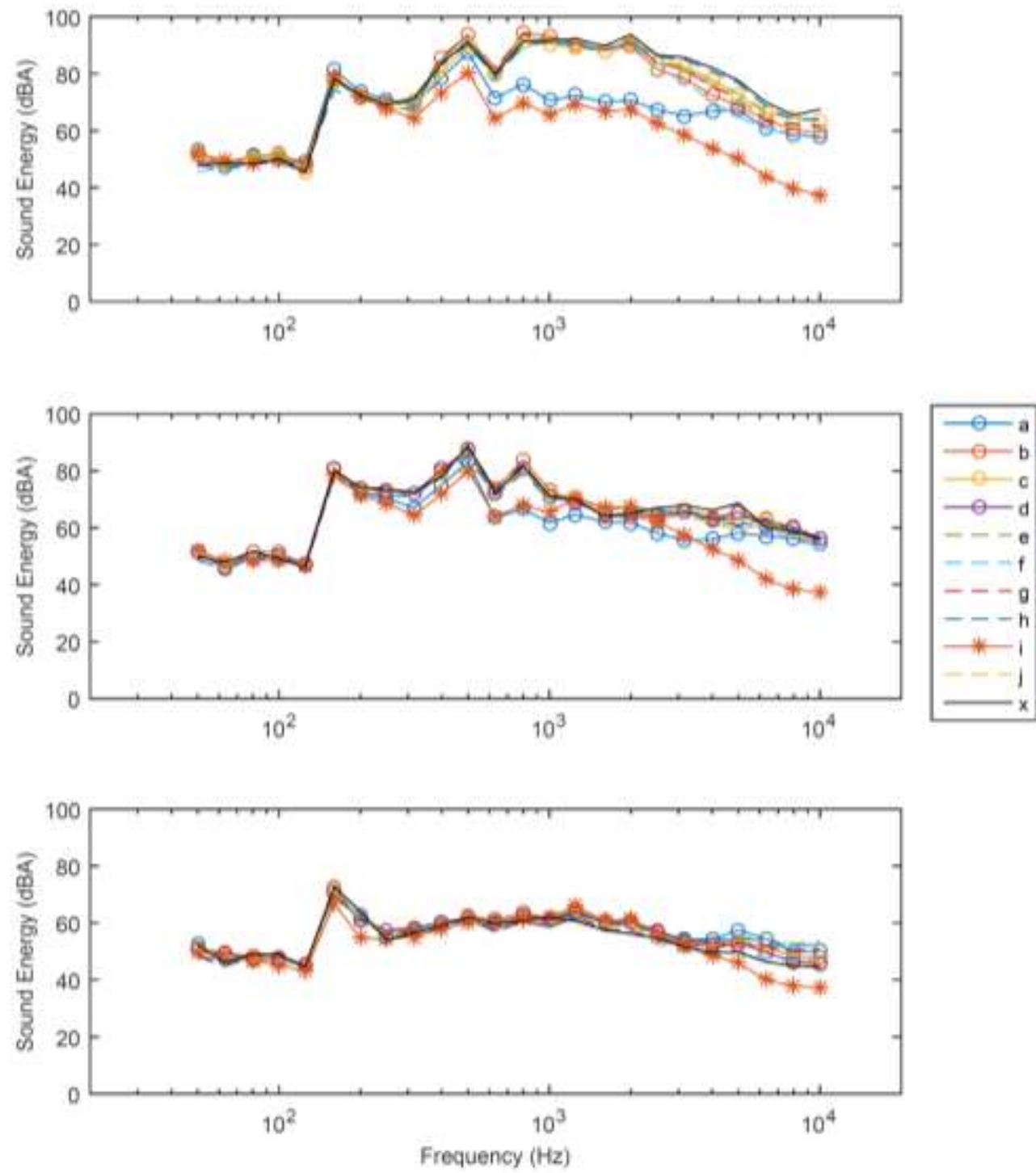

Figure 13: Measured impact sound energies in one third octave bands for the three impactor tips; steel tip (top), medium hard urethane tip (middle) and soft urethane tip (bottom) 

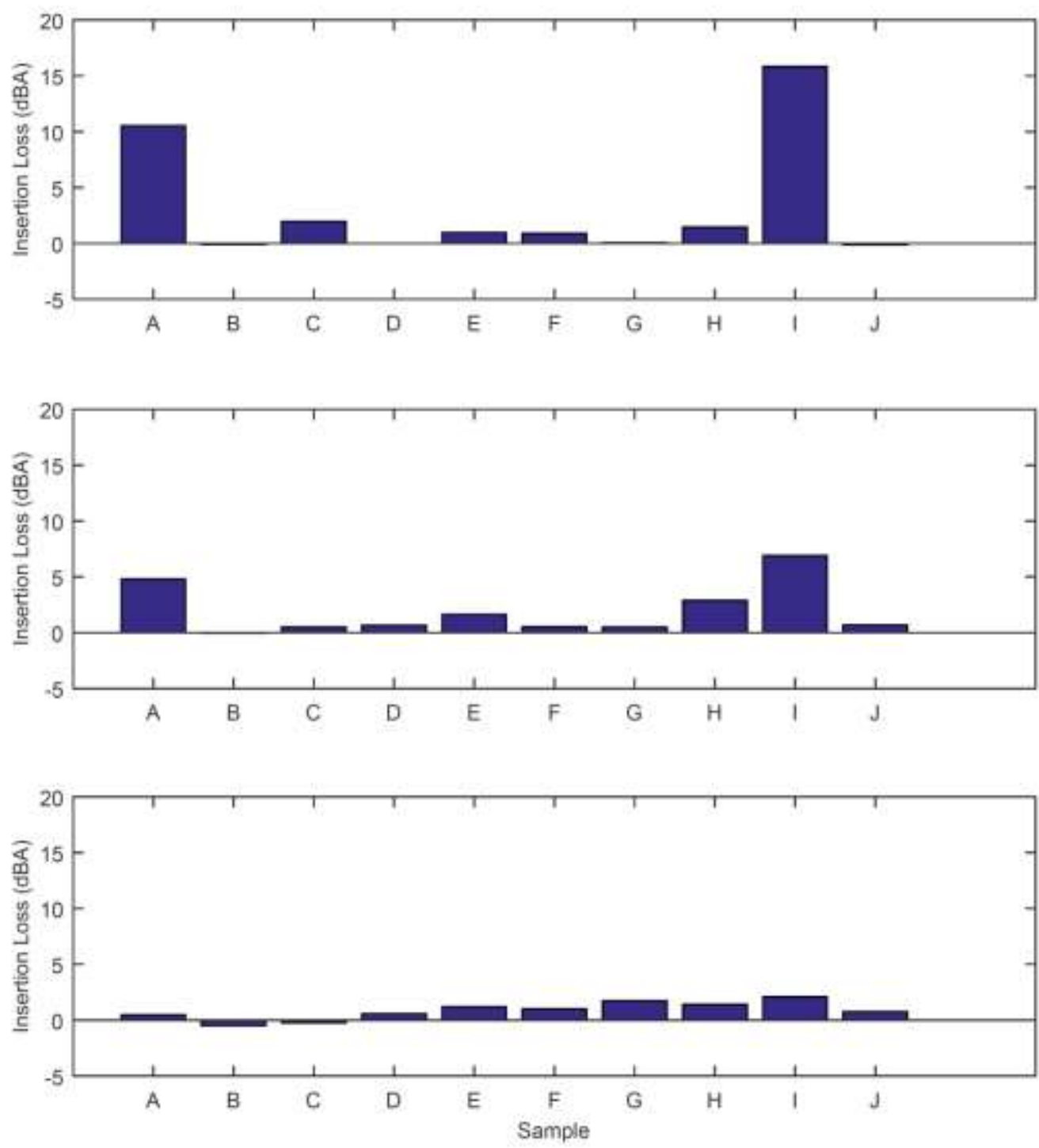

Figure 14: Insertion loss for samples A-J when impacted by a large heavy impactor. Top middle and bottom plots correspond to the steel, plastic and soft rubber impactor tips respectively.

It can be seen from Figure 14 that samples I and A provided the greatest insertion loss in this case (heavy impactor with a hard face). Overall, sound impact reductions were generally lower however than those obtained with the small exciter. This may be due to the the floor coverings behaving non-linearly and/or because the impactor faces were larger. Interestingly, sample A did not perform as well as carpet in these tests (the reverse of what was observed for the small impactor). This could in part be due to a 'slap' sound from sample A, possibly due to local deformation of the floor covering around the impact area (as also observed and discussed in the previous section). Carpet should be less prone to this type of deformation and laminate floor coverings would likely be more susceptible. 
Overall, it can be seen that only samples I and A had a significant effect on the sound energy generated by the large impact sound source, and that the noise from the very soft impactor was not significantly reduced by any of the floor coverings. This implies that the noise from very soft soled shoes is unlikely to be reduced significantly by any of the floor coverings themselves, especially when noise from local deformation of the floor itself is significant.

Due to the large area of floor tested with the large and small impactors, it is likely that ringing and acceleration noise from the concrete slab was often dominant (a transfer path analysis of this test setup was not conducted). This would likely also have masked any acceleration or ringing noise of the impacting object itself, which could be significant for some floor/object combinations. For this reason, a further test was also conducted using a smaller floor area in the semi anechoic chamber. The sound insertion loss results from these tests are presented in the following sub-section. 


\section{Spherical Steel Impactor}

Depending on the weight of the floor and the type of object being dropped, the floor itself or the impacting object may be the dominant source of noise. The dominant mechanism in either case could be acceleration noise, ringing noise or a combination of the two.

In order to investigate the influence of the floor coverings on acceleration noise, a hollow steel sphere, Figure 15, was used as an impact sound source. The test employed a smaller floor area than previous experiments: a concrete block $14.5 \mathrm{~cm} \times 14.5 \mathrm{~cm} \times 14.5 \mathrm{~cm}$ weighing $16.4 \mathrm{~kg}$, see Figure 3 . The diameter of the metal sphere was $100 \mathrm{~mm}$ and its mass when combined with the PTFE rod was $1 \mathrm{~kg}$. A drop height of $10 \mathrm{~cm}$ was used to measure the impact noise reduction.

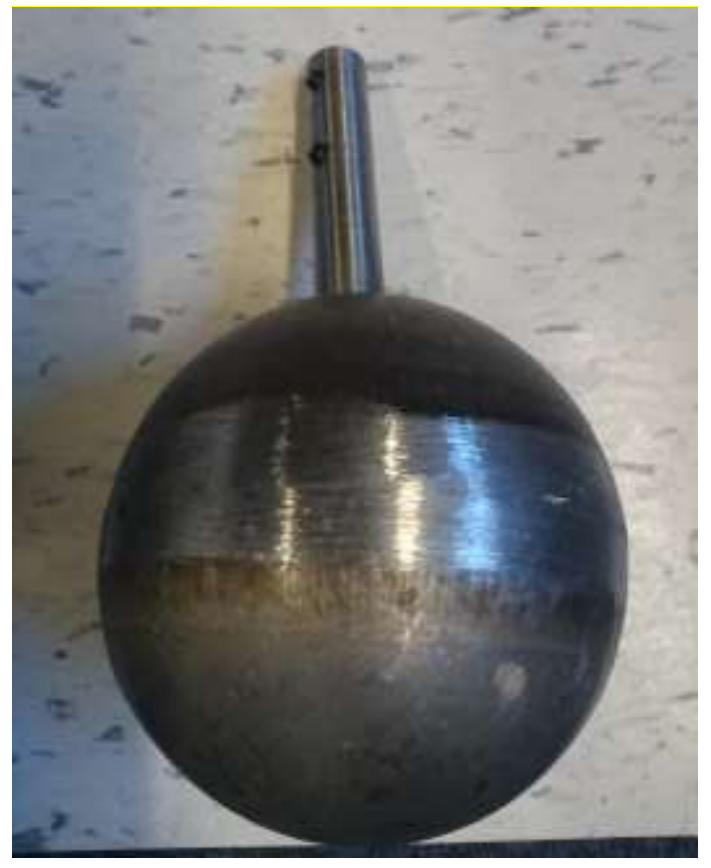

Figure 15: Photo of the hollow metal sphere impactor.

Shown in Figure 16 are the measured insertion losses for each floor sample tested. For each bar there is an error bound, plotted as \pm twice the standard deviation of the A-weighted impact energy in dBA. The solid blue bars give the mean value obtained and the red error bars give an indication of the associated uncertainty.

From the selection of random objects tested (book, chair leg and metal sphere) the metal sphere was the only object that was found to be repeatable as would be expected for a spherical object. 


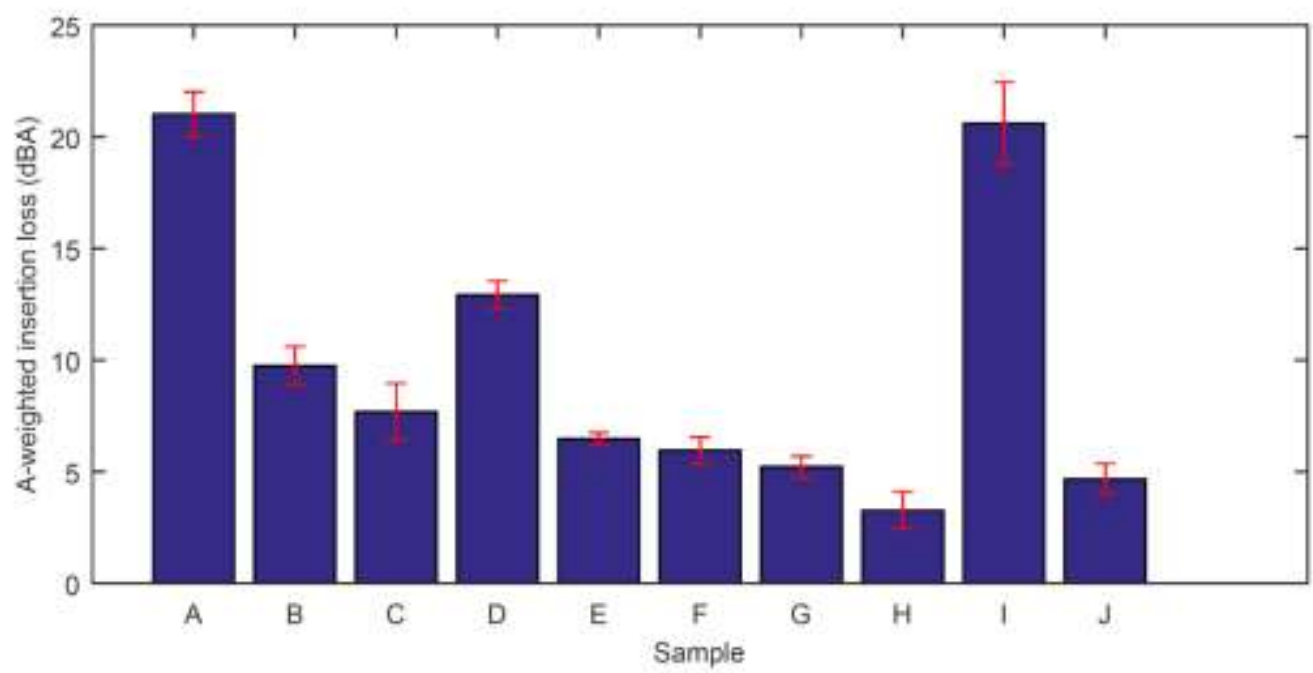

Figure 16: Insertion loss for the 10 floor coverings when using a hollow $10 \mathrm{~cm}$ ball as the impact sound source.

It can be seen in Figure 16 and in Table 2 below that samples $A$ and I gave the greatest impact sound reduction, followed by $D$ and $B$. The rank order of the samples according to Table 2 was found to be $A, I, D, B$, $C, E, F, G, J, H$. Bearing in mind the uncertainties, it may however be more appropriate to say that samples $A$ and I performed similarly, with the next best being sample D.

\begin{tabular}{|c|c|}
\hline Sample & A-Weighted Insertion loss (dBA) \\
\hline A & 21.0 \\
\hline B & 9.7 \\
\hline C & 7.7 \\
\hline D & 12.9 \\
\hline E & 6.5 \\
\hline F & 6.0 \\
\hline G & 5.2 \\
\hline H & 3.3 \\
\hline I & 20.6 \\
\hline J & 4.7 \\
\hline
\end{tabular}

Table 2: Impact noise insertion loss for 10 small sample area floor coverings impacted by a hollow steel ball. 


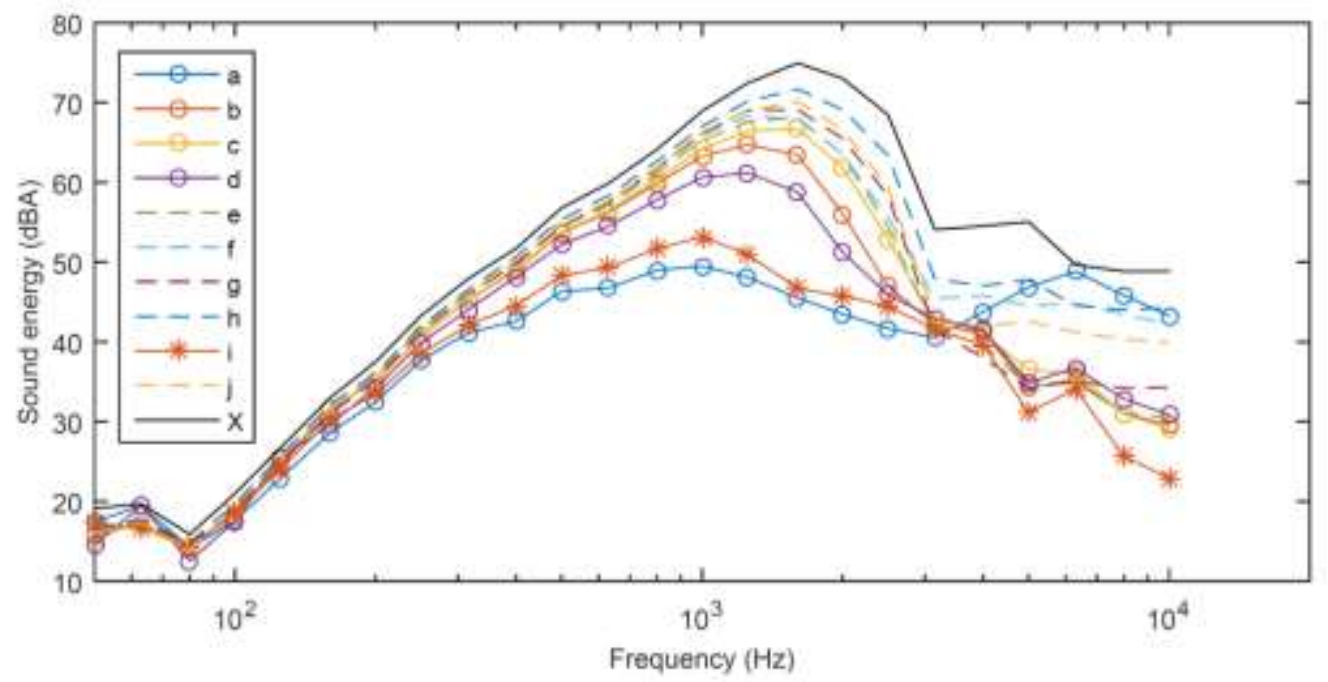

Figure 17: One third octave band sound energy spectrum for a hollow ball impactor on a small $14.5 \times 14.5 \mathrm{~cm}$ sample of floor covering applied to a solid concrete block.

Shown in Figure 17 are the A-weighted one third octave band sound energy levels that were used to calculate the overall A-weighted sound insertion losses given in Table 2. It is interesting to note that the magnitude of the sound energy around the peak value follows the same rank order A, I, D, B, C, E, F, G, J, H as it did for the force in Figure 12. This further suggests that force could be used as an indicator of the performance of a floor covering for in room impact noise reduction. It also implies the hierarchy is reliable because the data in Figure 12 and Figure 17 were obtained from different tests in different test environments, where noise from the floor and the impacting objects are likely to have differing relative magnitudes. However, again we see the unusual trend from sample $\mathrm{A}$ at higher frequencies, peaking in the $6300 \mathrm{~Hz}$ one third octave band. It would not be possible to identify this phenomenon by force or acceleration measurement and this would be a drawback of using force as a measure of in-room impact noise reduction. 


\section{Repeatability and Uncertainty}

So far in the paper multiple results have been presented for the in-room impact noise reduction for different floor coverings subjected to various impact loads. Because the work is of a research nature, i.e. the aim is to explore different methods for measuring in-room impact noise reduction rather than investigating any one specific method in detail, the uncertainties associated with the methods has not before this point been addressed in detail. It is nevertheless interesting to use what data is available from the different tests to provide an indication of the repeatability of the different impactor types. In this way, the more promising of methods can at least be qualitatively discussed which is likely to be of interest to any reader who may wish to experiment with similar approaches in the future.

In this section of the paper we look at the repeatability of the large and small impactors with different face materials and for different floor coverings (including the bare floor). Because the emphasis of the study was testing multiple floor materials in several different ways a minimum of three impacts was used for each test and the result presented in each case was the average level for the floor covering with respect to the average level for the bare floor.

The same area of the floor was used for each test and as such no data is available to demonstrate variability of the measured in-room impact noise reduction with respect to position. In terms of the method of excitation however it is arguably the repeatability of the excitation method which is of greatest research interest. In the following two sub-sections the repeatability of the large impactor and small impactor are addressed. In the third sub-section, differences which relate to the measurand (acceleration, force or sound pressure) are discussed qualitatively.

\section{Large Impactor}

The large impactor used in the study was mounted to a PTFE rod that was supported by two PTFE bearings to provide a low friction, and hence a repeatable drop and the faces of the impactors were slightly curved in order to provide a repeatable point of impact. Shown in Figure 18 is the repeatability of the impactor when the steel face was employed for floor covering $A$. The upper and lower plots in the figure show the repeatability in narrow and one-third-octave bands respectively. It can be seen that the measured sound pressure level recorded for each of the three impacts in this case were highly repeatable and this could no doubt be bettered further with improvements to the method used to perform the drop. For example, an automatic, remotely operated drop mechanism would avoid the requirement for someone to be in the test chamber (thus reducing background noise) as well as providing greater precision in drop height. 

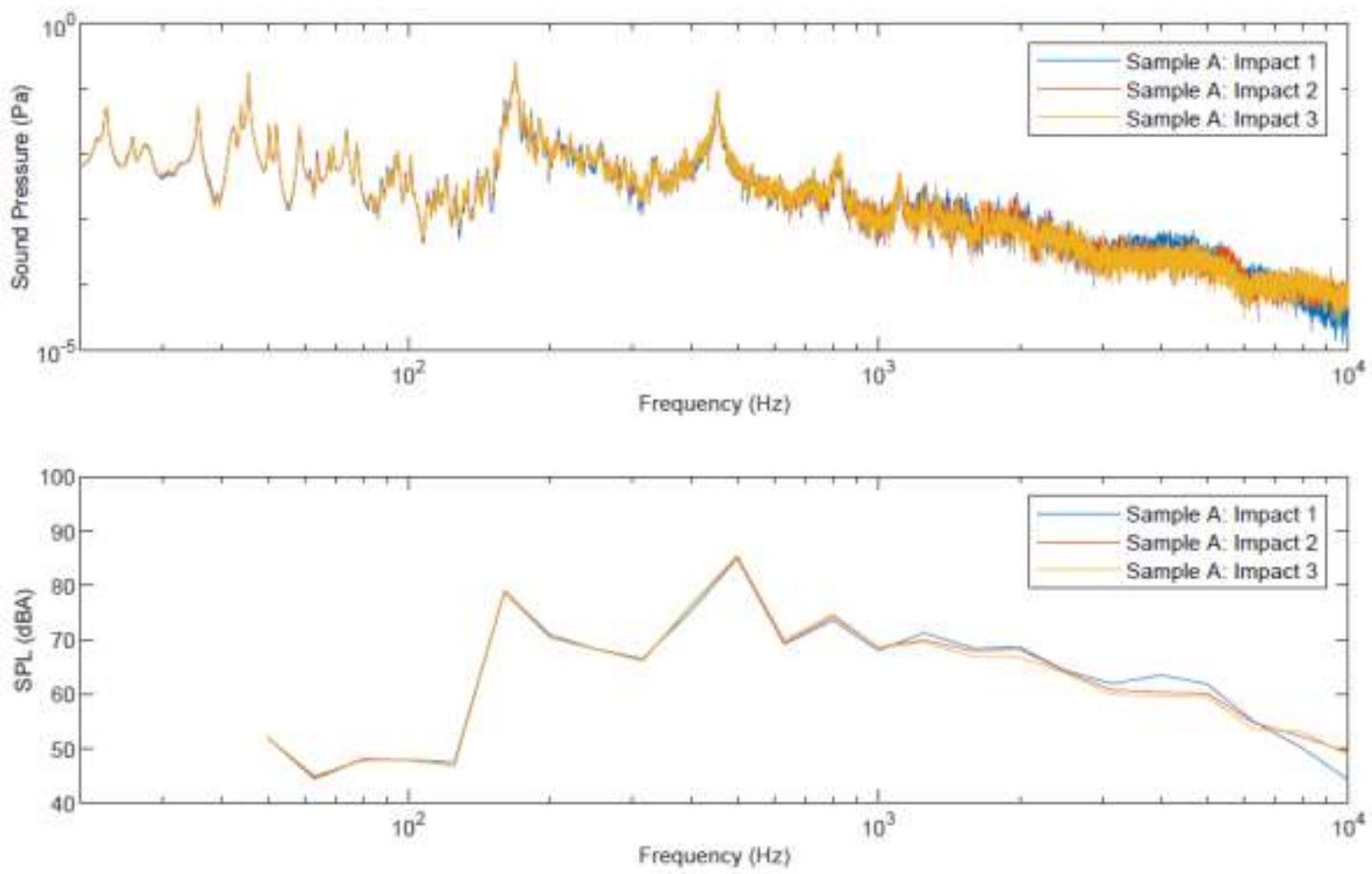

Figure 18: Repeatability of the large steel faced impactor for sample A. The upper plot shows the repeatability of the radiated sound pressure for three impacts on sample $A$ in narrowband. The lower plot presents the same data in one third octave bands.

Figure 19 shows the repeatability of the large impactor with different faces when impacting on the bare floor (in general it was found that measurements on the bare floor were the least repeatable). It can be seen that the repeatability of the bare floor test with the steel faced large impactor was the least repeatable. This is likely due to the severity of the impact, varying surface roughness at a very small scale and possibly non-linear behaviour. The variability of the bare floor results does not affect the rank ordering of the materials however because the same averaged bare floor measurement was used in each case as the reference for each of the floor coverings tested. In practice however, it would affect inter laboratory repeatability.

Due to the large quantity of data obtained it is not possible to present it all graphically in the paper, it is however possible to present the repeatability of the impacts in tabular form using the overall Aweighted sound pressure level for each of the impacts, for each of the surfaces and for each of the impact faces. 

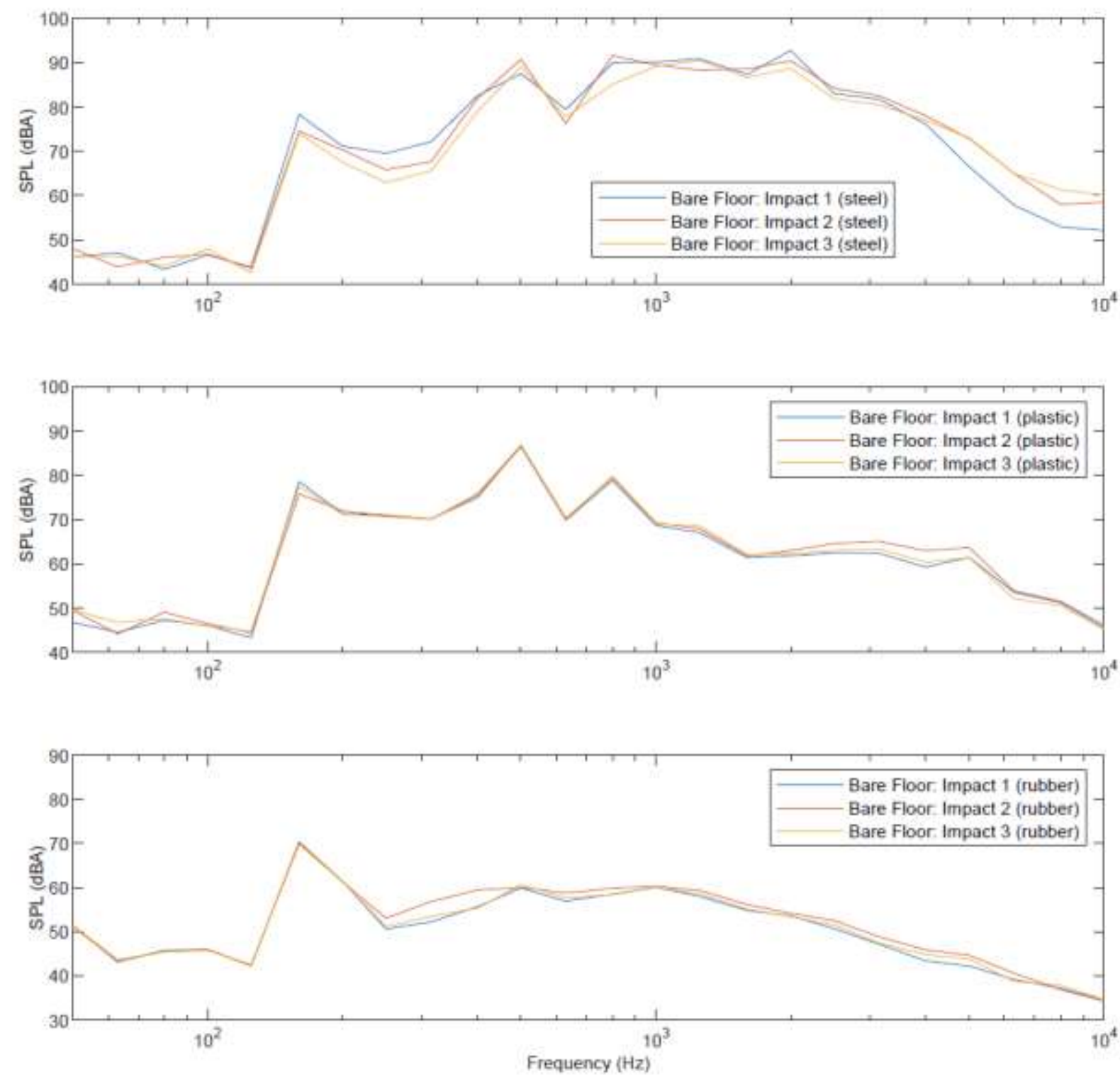

Figure 19: Repeatability of the large impactor for the bare floor (X). The top, middle and bottom plots correspond to the steel, plastic and rubber impactors respectively.

Table 3 shows the A-weighted impact sound pressure levels for all impacts made with the large impactor (note that no data is available for sample D with the steel tip due to data loss). Again it can be seen that measurements made with the steel tip were the least repeatable. The last column shows the maximum deviation from the mean sound pressure level for the three impacts which should be a good indicator of repeatability (albeit rather sensitive to outliers). Note that, A more rigorous analysis of the uncertainties would require a greater number of impacts than were employed in the study. Nevertheless, we may summarise the results in the table by noting that the average of all maximum deviations from the mean was $0.4 \mathrm{~dB}$ with a standard deviation also of $0.4 \mathrm{~dB}$ 
and if the steel tip was excluded from this analysis the average maximum deviation (which is a very sensitive measure) would be lower.

\begin{tabular}{|c|c|c|c|c|c|c|c|c|c|}
\hline & $\begin{array}{c}\text { Sample } \\
\text { (Reference label) }\end{array}$ & $\begin{array}{c}\text { Impact } 1 \\
\text { (dB) }\end{array}$ & $\begin{array}{c}\text { Impact } 2 \\
\text { (dB) }\end{array}$ & $\begin{array}{c}\text { Impact } 3 \\
\text { (dB) }\end{array}$ & $\begin{array}{c}\text { Mean } \\
\text { (dB) }\end{array}$ & $\begin{array}{l}|\Delta 1| \\
(d B)\end{array}$ & $\begin{array}{l}|\Delta \mathbf{\Delta}| \\
(\mathrm{dB})\end{array}$ & $\begin{array}{l}|\Delta 3| \\
(\mathrm{dB})\end{array}$ & $\begin{array}{c}\left|\Delta_{\max }\right| \\
(\mathrm{dB})\end{array}$ \\
\hline \multirow{11}{*}{$\begin{array}{l}\stackrel{\varrho}{\stackrel{\varrho}{=}} \\
\frac{\Phi}{\Phi} \\
\stackrel{\Delta}{n}\end{array}$} & A & 87.2 & 87.3 & 87.5 & 87.4 & 0.2 & 0.0 & 0.2 & 0.2 \\
\hline & B & 97.1 & 99.4 & 97.1 & 98.0 & 0.9 & 1.4 & 0.9 & 1.4 \\
\hline & C & 96.1 & 96.7 & 94.7 & 95.9 & 0.2 & 0.8 & 1.2 & 1.2 \\
\hline & D & - & - & - & - & - & - & - & - \\
\hline & E & 95.3 & 96.6 & 99.5 & 97.5 & 2.2 & 0.9 & 2.0 & 2.2 \\
\hline & $\mathbf{F}$ & 98.2 & 97.0 & 96.3 & 97.2 & 1.0 & 0.3 & 0.9 & 1.0 \\
\hline & G & 98.6 & 98.7 & 98.1 & 98.5 & 0.1 & 0.2 & 0.4 & 0.4 \\
\hline & H & 96.5 & 95.6 & 96.8 & 96.3 & 0.2 & 0.7 & 0.5 & 0.7 \\
\hline & $\mathbf{I}$ & 81.6 & 81.8 & 82.2 & 81.9 & 0.3 & 0.1 & 0.3 & 0.3 \\
\hline & J & 97.4 & 99.5 & 96.9 & 98.1 & 0.7 & 1.4 & 1.2 & 1.4 \\
\hline & $x$ & 98.5 & 98.3 & 96.8 & 97.9 & 0.5 & 0.4 & 1.1 & 1.1 \\
\hline \multirow{11}{*}{ 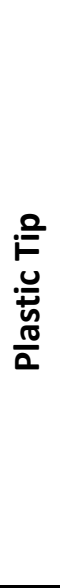 } & A & 83.5 & 83.4 & 83.4 & 83.4 & 0.1 & 0.0 & 0.1 & 0.1 \\
\hline & B & 88.0 & 88.1 & 88.5 & 88.2 & 0.3 & 0.1 & 0.3 & 0.3 \\
\hline & C & 88.8 & 87.2 & 87.8 & 88.0 & 0.8 & 0.8 & 0.2 & 0.8 \\
\hline & D & 87.4 & 89.0 & 87.7 & 88.1 & 0.7 & 0.9 & 0.4 & 0.9 \\
\hline & $E$ & 87.0 & 86.6 & 87.1 & 86.9 & 0.1 & 0.3 & 0.2 & 0.3 \\
\hline & $\mathbf{F}$ & 87.9 & 87.5 & 88.2 & 87.9 & 0.0 & 0.4 & 0.4 & 0.4 \\
\hline & G & 88.8 & 87.6 & 88.0 & 88.2 & 0.6 & 0.6 & 0.1 & 0.6 \\
\hline & $\mathbf{H}$ & 85.6 & 85.7 & 85.8 & 85.7 & 0.1 & 0.0 & 0.1 & 0.1 \\
\hline & $I$ & 80.8 & 81.5 & 82.0 & 81.5 & 0.7 & 0.1 & 0.5 & 0.7 \\
\hline & $\mathbf{J}$ & 87.9 & 87.4 & 88.2 & 87.8 & 0.0 & 0.4 & 0.3 & 0.4 \\
\hline & $x$ & 88.4 & 88.6 & 88.6 & 88.5 & 0.1 & 0.0 & 0.1 & 0.1 \\
\hline \multirow{11}{*}{ 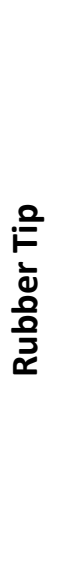 } & A & 72.2 & 71.5 & 72.0 & 71.9 & 0.3 & 0.4 & 0.1 & 0.4 \\
\hline & B & 73.0 & 73.5 & 72.6 & 73.0 & 0.1 & 0.4 & 0.4 & 0.4 \\
\hline & C & 72.7 & 72.6 & 73.0 & 72.8 & 0.1 & 0.2 & 0.3 & 0.3 \\
\hline & D & 72.3 & 71.8 & 71.8 & 72.0 & 0.3 & 0.2 & 0.2 & 0.3 \\
\hline & $\mathbf{E}$ & 70.8 & 71.4 & 71.2 & 71.1 & 0.4 & 0.3 & 0.1 & 0.4 \\
\hline & $\mathbf{F}$ & 71.9 & 71.1 & 71.8 & 71.6 & 0.3 & 0.5 & 0.2 & 0.5 \\
\hline & G & 71.5 & 70.2 & 70.5 & 70.8 & 0.7 & 0.5 & 0.3 & 0.7 \\
\hline & H & 71.1 & 71.0 & 71.4 & 71.2 & 0.0 & 0.2 & 0.2 & 0.2 \\
\hline & 1 & 69.6 & 71.1 & 71.4 & 70.7 & 1.2 & 0.4 & 0.6 & 1.2 \\
\hline & J & 72.5 & 71.4 & 71.8 & 71.9 & 0.5 & 0.5 & 0.1 & 0.5 \\
\hline & $x$ & 72.4 & 72.8 & 72.2 & 72.5 & 0.1 & 0.3 & 0.3 & 0.3 \\
\hline
\end{tabular}

Table 3: Impact sound pressure levels for three individual impacts using the large impactor. The table shows results for each of the hammer tips used and for every floor covering tested, including the bare floor.

Column 6 shows the mean sound pressure level and column 10 shows the maximum deviation $\Delta$ from the mean sound pressure level for the three impacts shown. 


\section{Small Impactor}

A similar repeatability analysis was performed for the small impactor as was conducted for large impactor. In this case however three drop heights were employed so the data set was three times larger but still with only three impacts per test iteration. Results showing the repeatability of impacts for the different impact faces with sample A and with the bare floor are shown in Figure 20 and Figure 21 respectively.
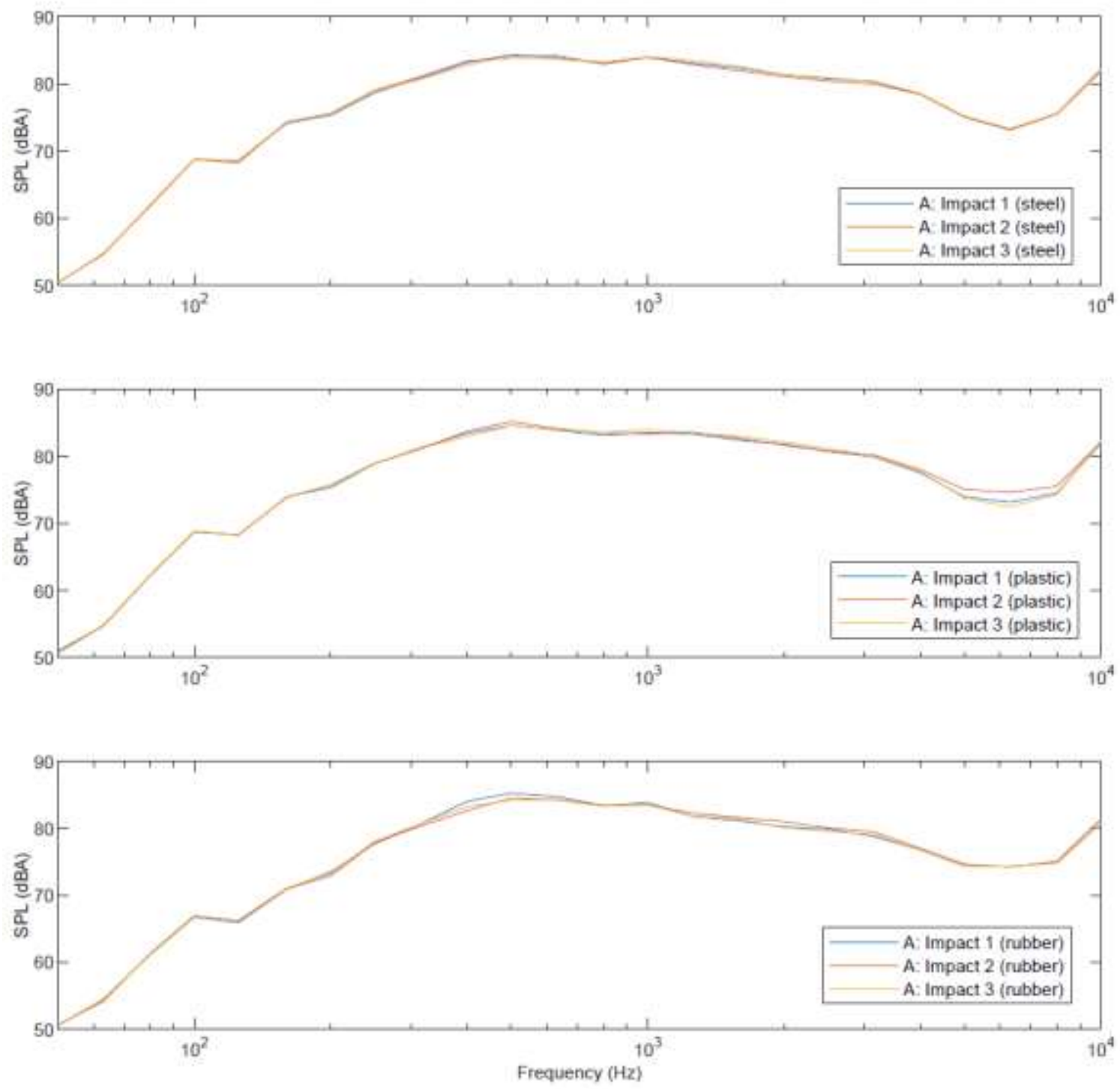

Figure 20: Repeatability of three impacts of the small impactor on the bare floor for the steel, plastic and rubber tips in one-third-octave bands. The drop height used was $50 \mathrm{~cm}$ and the impactor was allowed to bounce. 

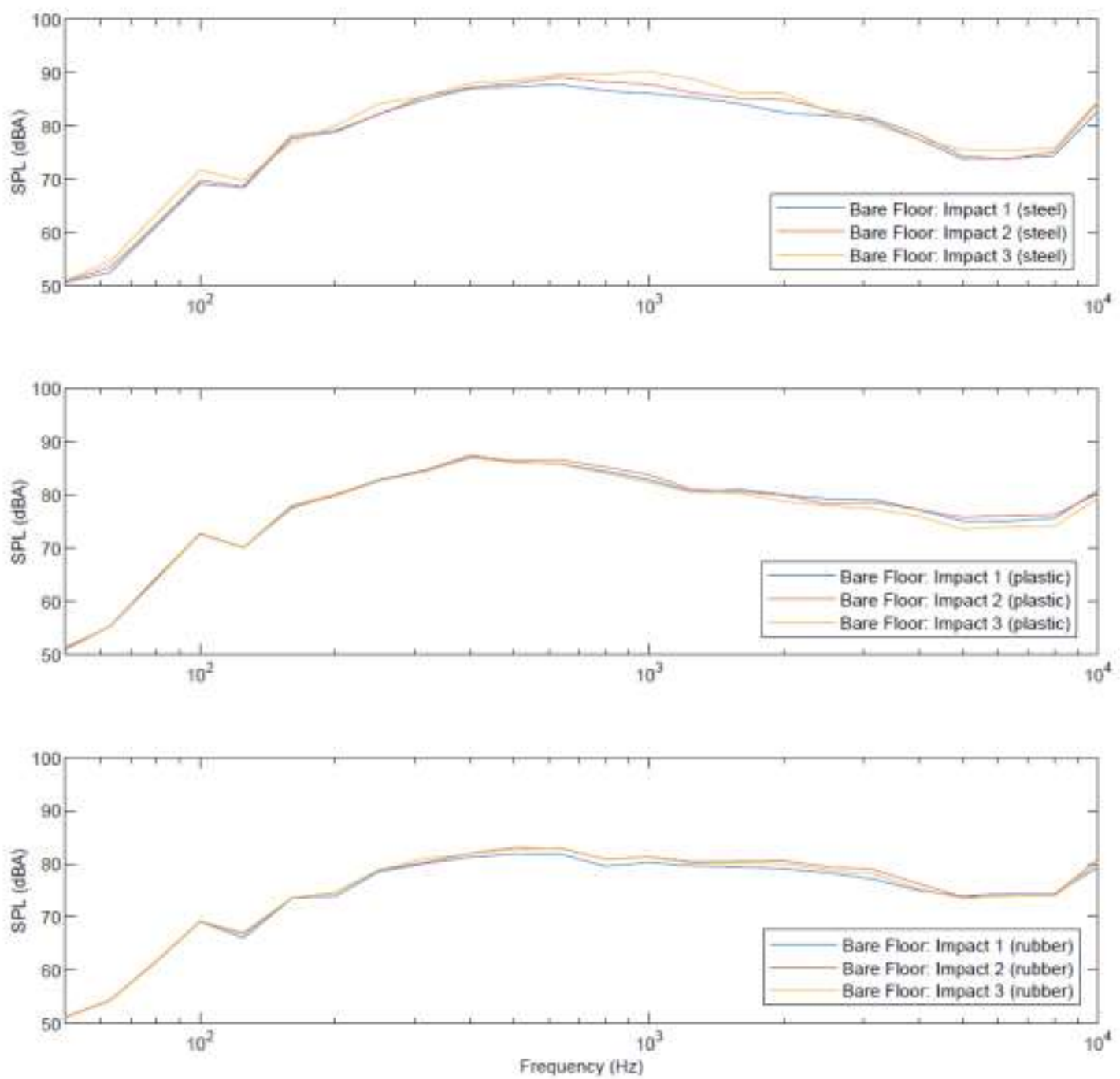

Figure 21: Repeatability of three impacts of the small impactor on the bare floor for the steel, plastic and rubber tips in one-third-octave bands. The drop height used was $50 \mathrm{~cm}$ and the impactor was allowed to bounce.

The small impactor dataset was also tabulated using the overall A-weighted sound levels for each of the drop heights $10 \mathrm{~cm}, 30 \mathrm{~cm}$ and $50 \mathrm{~cm}$ as shown in Table 4 to Table 6 respectively. Again, there are a few tests where there is a strong outlier, which strongly effects the max deviation from the mean, and the harder tip appears most sensitive. Overall though, the small impactor appears to be more repeatable than the heavy impactor with the average maximum deviation from the mean being $0.3 \mathrm{~dB}$ with a standard deviation of $0.3 \mathrm{~dB}$. 


\begin{tabular}{|c|c|c|c|c|c|c|c|c|c|}
\hline & $\begin{array}{c}\text { Sample } \\
\text { (Reference label) }\end{array}$ & $\begin{array}{l}\text { Impact } 1 \\
\text { (dB) }\end{array}$ & $\begin{array}{c}\text { Impact } 2 \\
\text { (dB) }\end{array}$ & $\begin{array}{c}\text { Impact } 3 \\
\text { (dB) }\end{array}$ & $\begin{array}{l}\text { Mean } \\
\text { (dB) }\end{array}$ & $\begin{array}{l}|\Delta 1| \\
(\mathrm{dB})\end{array}$ & $\begin{array}{l}|\Delta 2| \\
(d B)\end{array}$ & $\begin{array}{l}|\Delta 3| \\
(\mathrm{dB})\end{array}$ & $\begin{array}{c}\left|\Delta_{\max }\right| \\
(\mathrm{dB})\end{array}$ \\
\hline \multirow{11}{*}{$\begin{array}{l}\stackrel{\varrho}{\underline{E}} \\
\bar{\Phi} \\
\stackrel{\Phi}{\omega}\end{array}$} & A & 89.1 & 89.3 & 89.7 & 89.4 & 0.3 & 0.1 & 0.3 & 0.3 \\
\hline & B & 88.6 & 88.2 & 88.6 & 88.5 & 0.2 & 0.3 & 0.1 & 0.3 \\
\hline & C & 89.1 & 89.2 & 89.0 & 89.1 & 0.0 & 0.1 & 0.1 & 0.1 \\
\hline & D & 87.1 & 86.9 & 86.7 & 86.9 & 0.2 & 0.0 & 0.2 & 0.2 \\
\hline & $\mathbf{E}$ & 91.4 & 91.3 & 91.3 & 91.4 & 0.1 & 0.0 & 0.0 & 0.1 \\
\hline & $\mathbf{F}$ & 90.7 & 90.6 & 90.1 & 90.5 & 0.2 & 0.1 & 0.3 & 0.3 \\
\hline & $\mathbf{G}$ & 92.2 & 89.9 & 90.9 & 91.1 & 1.1 & 1.2 & 0.2 & 1.2 \\
\hline & H & 92.1 & 92.3 & 92.6 & 92.3 & 0.2 & 0.1 & 0.3 & 0.3 \\
\hline & 1 & 86.9 & 87.8 & 87.1 & 87.3 & 0.4 & 0.5 & 0.2 & 0.5 \\
\hline & J & 90.6 & 89.8 & 90.3 & 90.2 & 0.3 & 0.5 & 0.1 & 0.5 \\
\hline & $x$ & 93.2 & 95.5 & 95.4 & 94.9 & 1.6 & 0.7 & 0.6 & 1.6 \\
\hline \multirow{11}{*}{ 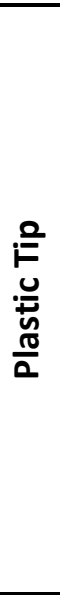 } & $A$ & 89.6 & 89.3 & 90.1 & 89.7 & 0.1 & 0.4 & 0.4 & 0.4 \\
\hline & B & 86.6 & 89.3 & 88.3 & 88.2 & 1.6 & 1.1 & 0.1 & 1.6 \\
\hline & C & 89.0 & 88.4 & 88.9 & 88.8 & 0.2 & 0.4 & 0.1 & 0.4 \\
\hline & D & 88.0 & 86.7 & 86.9 & 87.2 & 0.8 & 0.6 & 0.4 & 0.8 \\
\hline & E & 90.8 & 91.1 & 91.9 & 91.3 & 0.5 & 0.2 & 0.6 & 0.6 \\
\hline & $\mathbf{F}$ & 90.7 & 92.8 & 92.3 & 92.0 & 1.3 & 0.8 & 0.3 & 1.3 \\
\hline & $\mathbf{G}$ & 87.9 & 88.7 & 89.6 & 88.8 & 0.9 & 0.1 & 0.8 & 0.9 \\
\hline & $\mathbf{H}$ & 89.8 & 90.1 & 90.0 & 90.0 & 0.1 & 0.1 & 0.0 & 0.1 \\
\hline & I & 86.5 & 86.7 & 86.8 & 86.7 & 0.2 & 0.0 & 0.1 & 0.2 \\
\hline & $\mathbf{J}$ & 89.2 & 90.7 & 89.9 & 90.0 & 0.8 & 0.7 & 0.1 & 0.8 \\
\hline & $x$ & 89.7 & 89.6 & 89.5 & 89.6 & 0.1 & 0.0 & 0.1 & 0.1 \\
\hline \multirow{11}{*}{ 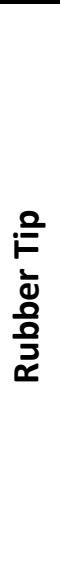 } & A & 88.4 & 88.5 & 88.0 & 88.3 & 0.1 & 0.2 & 0.3 & 0.3 \\
\hline & B & 87.6 & 87.4 & 87.3 & 87.4 & 0.1 & 0.0 & 0.1 & 0.1 \\
\hline & C & 87.8 & 87.6 & 87.6 & 87.7 & 0.1 & 0.1 & 0.0 & 0.1 \\
\hline & D & 86.0 & 86.4 & 86.7 & 86.4 & 0.4 & 0.0 & 0.3 & 0.4 \\
\hline & $E$ & 90.1 & 90.1 & 90.3 & 90.2 & 0.1 & 0.1 & 0.1 & 0.1 \\
\hline & $\mathbf{F}$ & 87.4 & 87.2 & 87.2 & 87.3 & 0.1 & 0.1 & 0.1 & 0.1 \\
\hline & $\mathbf{G}$ & 87.2 & 87.7 & 87.2 & 87.4 & 0.2 & 0.3 & 0.2 & 0.3 \\
\hline & $\mathbf{H}$ & 88.0 & 87.9 & 88.0 & 88.0 & 0.0 & 0.1 & 0.1 & 0.1 \\
\hline & 1 & 86.9 & 86.8 & 86.7 & 86.8 & 0.1 & 0.0 & 0.1 & 0.1 \\
\hline & $\mathbf{J}$ & 87.2 & 90.4 & 89.7 & 89.3 & 2.1 & 1.1 & 0.4 & 2.1 \\
\hline & $x$ & 86.5 & 86.3 & 86.2 & 86.3 & 0.2 & 0.0 & 0.2 & 0.2 \\
\hline
\end{tabular}

Table 4: Impact sound pressure levels for three individual impacts using the small impactor with a drop height of $10 \mathrm{~cm}$. The table shows results for each of the hammer tips used and for every floor covering tested, including the bare floor. Column 6 shows the mean sound pressure level and column 10 shows the maximum deviation $\Delta$ from the mean sound pressure level for the three impacts shown. 


\begin{tabular}{|c|c|c|c|c|c|c|c|c|c|}
\hline & $\begin{array}{c}\text { Sample } \\
\text { (Reference label) }\end{array}$ & $\begin{array}{l}\text { Impact } 1 \\
\text { (dB) }\end{array}$ & $\begin{array}{c}\text { Impact } 2 \\
\text { (dB) }\end{array}$ & $\begin{array}{c}\text { Impact } 3 \\
\text { (dB) }\end{array}$ & $\begin{array}{l}\text { Mean } \\
\text { (dB) }\end{array}$ & $\begin{array}{l}|\Delta 1| \\
(\mathrm{dB})\end{array}$ & $\begin{array}{l}|\Delta 2| \\
(\mathrm{dB})\end{array}$ & $\begin{array}{l}|\Delta 3| \\
(\mathrm{dB})\end{array}$ & $\begin{array}{c}\left|\Delta_{\max }\right| \\
(\mathrm{dB})\end{array}$ \\
\hline \multirow{11}{*}{$\begin{array}{l}\stackrel{\varrho}{\underline{E}} \\
\bar{\Phi} \\
\stackrel{\Phi}{\omega}\end{array}$} & A & 92.1 & 92.7 & 92.9 & 92.6 & 0.5 & 0.1 & 0.3 & 0.5 \\
\hline & B & 92.3 & 92.3 & 91.9 & 92.2 & 0.1 & 0.1 & 0.3 & 0.3 \\
\hline & C & 92.8 & 92.3 & 92.7 & 92.6 & 0.2 & 0.3 & 0.1 & 0.3 \\
\hline & D & 90.8 & 91.7 & 91.0 & 91.2 & 0.3 & 0.5 & 0.2 & 0.5 \\
\hline & $\mathbf{E}$ & 93.4 & 93.4 & 93.4 & 93.4 & 0.0 & 0.0 & 0.0 & 0.0 \\
\hline & $\mathbf{F}$ & 94.0 & 94.7 & 93.9 & 94.2 & 0.2 & 0.5 & 0.3 & 0.5 \\
\hline & $\mathbf{G}$ & 93.5 & 92.9 & 93.0 & 93.1 & 0.4 & 0.3 & 0.1 & 0.4 \\
\hline & H & 95.9 & 95.8 & 94.7 & 95.5 & 0.4 & 0.3 & 0.8 & 0.8 \\
\hline & 1 & 90.2 & 90.2 & 91.0 & 90.5 & 0.3 & 0.3 & 0.5 & 0.5 \\
\hline & J & 94.3 & 94.4 & 94.4 & 94.4 & 0.1 & 0.1 & 0.0 & 0.1 \\
\hline & $x$ & 96.6 & 97.3 & 96.0 & 96.7 & 0.1 & 0.7 & 0.7 & 0.7 \\
\hline \multirow{11}{*}{ 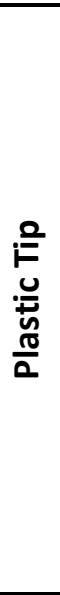 } & $A$ & 92.1 & 92.7 & 92.9 & 92.6 & 0.5 & 0.1 & 0.3 & 0.5 \\
\hline & B & 91.9 & 91.9 & 92.5 & 92.1 & 0.2 & 0.2 & 0.4 & 0.4 \\
\hline & C & 92.9 & 92.3 & 92.6 & 92.6 & 0.3 & 0.3 & 0.0 & 0.3 \\
\hline & D & 91.0 & 91.2 & 91.1 & 91.1 & 0.1 & 0.1 & 0.0 & 0.1 \\
\hline & E & 92.8 & 92.8 & 92.7 & 92.8 & 0.0 & 0.0 & 0.1 & 0.1 \\
\hline & $\mathbf{F}$ & 93.7 & 93.6 & 93.4 & 93.5 & 0.1 & 0.0 & 0.2 & 0.2 \\
\hline & $\mathbf{G}$ & 92.6 & 92.6 & 92.5 & 92.6 & 0.0 & 0.0 & 0.0 & 0.0 \\
\hline & $\mathbf{H}$ & 94.4 & 94.5 & 94.9 & 94.6 & 0.2 & 0.1 & 0.3 & 0.3 \\
\hline & I & 91.1 & 91.2 & 90.8 & 91.0 & 0.1 & 0.2 & 0.3 & 0.3 \\
\hline & $\mathbf{J}$ & 94.1 & 93.9 & 94.3 & 94.1 & 0.0 & 0.2 & 0.2 & 0.2 \\
\hline & $x$ & 93.2 & 93.6 & 94.0 & 93.6 & 0.4 & 0.0 & 0.4 & 0.4 \\
\hline \multirow{11}{*}{ 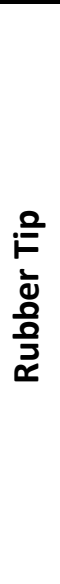 } & A & 91.9 & 92.7 & 91.6 & 92.1 & 0.2 & 0.6 & 0.5 & 0.6 \\
\hline & B & 91.5 & 91.5 & 91.7 & 91.6 & 0.1 & 0.1 & 0.1 & 0.1 \\
\hline & C & 91.9 & 91.0 & 91.1 & 91.4 & 0.5 & 0.3 & 0.2 & 0.5 \\
\hline & D & 90.6 & 91.3 & 91.0 & 91.0 & 0.4 & 0.3 & 0.0 & 0.4 \\
\hline & $E$ & 91.5 & 91.5 & 91.9 & 91.6 & 0.1 & 0.1 & 0.2 & 0.2 \\
\hline & $\mathbf{F}$ & 92.3 & 92.0 & 91.5 & 91.9 & 0.4 & 0.0 & 0.5 & 0.5 \\
\hline & $\mathbf{G}$ & 91.2 & 91.4 & 91.8 & 91.5 & 0.2 & 0.1 & 0.3 & 0.3 \\
\hline & $\mathbf{H}$ & 92.4 & 90.9 & 91.2 & 91.5 & 0.8 & 0.6 & 0.3 & 0.8 \\
\hline & 1 & 90.4 & 91.2 & 90.7 & 90.8 & 0.3 & 0.4 & 0.1 & 0.4 \\
\hline & $\mathbf{J}$ & 91.9 & 92.3 & 92.0 & 92.1 & 0.2 & 0.2 & 0.1 & 0.2 \\
\hline & $x$ & 89.9 & 90.0 & 90.2 & 90.0 & 0.1 & 0.1 & 0.2 & 0.2 \\
\hline
\end{tabular}

Table 5: Impact sound pressure levels for three individual impacts using the small impactor with a drop height of $30 \mathrm{~cm}$. The table shows results for each of the hammer tips used and for every floor covering tested, including the bare floor. Column 6 shows the mean sound pressure level and column 10 shows the maximum deviation $\Delta$ from the mean sound pressure level for the three impacts shown. 


\begin{tabular}{|c|c|c|c|c|c|c|c|c|c|}
\hline & $\begin{array}{c}\text { Sample } \\
\text { (Reference label) }\end{array}$ & $\begin{array}{l}\text { Impact } 1 \\
\text { (dB) }\end{array}$ & $\begin{array}{c}\text { Impact } 2 \\
\text { (dB) }\end{array}$ & $\begin{array}{c}\text { Impact } 3 \\
\text { (dB) }\end{array}$ & $\begin{array}{l}\text { Mean } \\
\text { (dB) }\end{array}$ & $\begin{array}{l}|\Delta 1| \\
(\mathrm{dB})\end{array}$ & $\begin{array}{l}|\Delta \mathbf{2}| \\
(\mathrm{dB})\end{array}$ & $\begin{array}{l}|\Delta 3| \\
(\mathrm{dB})\end{array}$ & $\begin{array}{c}\left|\Delta_{\max }\right| \\
(\mathrm{dB})\end{array}$ \\
\hline \multirow{11}{*}{$\begin{array}{l}\stackrel{\varrho}{\underline{E}} \\
\bar{\Phi} \\
\stackrel{\Phi}{\omega}\end{array}$} & A & 94.0 & 93.9 & 94.0 & 94.0 & 0.0 & 0.1 & 0.0 & 0.1 \\
\hline & B & 93.3 & 93.7 & 93.8 & 93.6 & 0.3 & 0.1 & 0.2 & 0.3 \\
\hline & C & 94.1 & 93.6 & 94.1 & 93.9 & 0.1 & 0.3 & 0.2 & 0.3 \\
\hline & D & 92.9 & 93.7 & 92.9 & 93.2 & 0.2 & 0.5 & 0.3 & 0.5 \\
\hline & $\mathbf{E}$ & 93.7 & 94.0 & 95.3 & 94.4 & 0.7 & 0.4 & 0.9 & 0.9 \\
\hline & $\mathbf{F}$ & 95.8 & 95.6 & 95.4 & 95.6 & 0.2 & 0.0 & 0.2 & 0.2 \\
\hline & $\mathbf{G}$ & 94.3 & 95.0 & 94.7 & 94.7 & 0.4 & 0.3 & 0.0 & 0.4 \\
\hline & H & 96.3 & 96.0 & 96.3 & 96.2 & 0.1 & 0.2 & 0.1 & 0.2 \\
\hline & 1 & 94.0 & 94.2 & 94.0 & 94.1 & 0.1 & 0.1 & 0.1 & 0.1 \\
\hline & J & 95.0 & 95.6 & 95.3 & 95.3 & 0.3 & 0.3 & 0.0 & 0.3 \\
\hline & $x$ & 96.6 & 97.6 & 98.7 & 97.7 & 1.1 & 0.1 & 1.0 & 1.1 \\
\hline \multirow{11}{*}{ 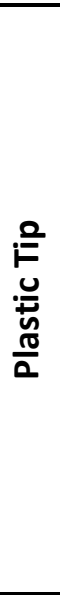 } & $A$ & 94.0 & 94.2 & 94.1 & 94.1 & 0.1 & 0.1 & 0.0 & 0.1 \\
\hline & B & 93.5 & 93.3 & 93.3 & 93.4 & 0.1 & 0.1 & 0.1 & 0.1 \\
\hline & C & 94.5 & 94.0 & 94.3 & 94.3 & 0.2 & 0.3 & 0.0 & 0.3 \\
\hline & D & 92.9 & 93.1 & 93.3 & 93.1 & 0.2 & 0.0 & 0.2 & 0.2 \\
\hline & E & 93.8 & 94.3 & 94.0 & 94.0 & 0.2 & 0.3 & 0.0 & 0.3 \\
\hline & $\mathbf{F}$ & 95.2 & 94.7 & 94.5 & 94.8 & 0.3 & 0.1 & 0.3 & 0.3 \\
\hline & $\mathbf{G}$ & 94.7 & 94.3 & 94.9 & 94.6 & 0.0 & 0.3 & 0.3 & 0.3 \\
\hline & $\mathbf{H}$ & 95.6 & 95.1 & 95.7 & 95.5 & 0.1 & 0.4 & 0.2 & 0.4 \\
\hline & I & 94.1 & 93.7 & 94.1 & 94.0 & 0.1 & 0.3 & 0.1 & 0.3 \\
\hline & $\mathbf{J}$ & 95.5 & 95.9 & 95.6 & 95.7 & 0.2 & 0.2 & 0.0 & 0.2 \\
\hline & $x$ & 95.1 & 95.4 & 94.8 & 95.1 & 0.0 & 0.3 & 0.3 & 0.3 \\
\hline \multirow{11}{*}{ 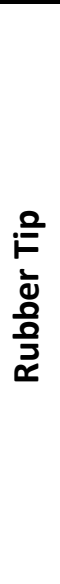 } & A & 93.7 & 93.6 & 93.4 & 93.6 & 0.1 & 0.0 & 0.1 & 0.1 \\
\hline & B & 93.3 & 93.0 & 93.3 & 93.2 & 0.1 & 0.2 & 0.1 & 0.2 \\
\hline & C & 93.4 & 94.0 & 93.7 & 93.7 & 0.3 & 0.3 & 0.0 & 0.3 \\
\hline & D & 92.8 & 93.3 & 92.7 & 92.9 & 0.2 & 0.4 & 0.3 & 0.4 \\
\hline & $E$ & 93.4 & 93.5 & 93.5 & 93.5 & 0.1 & 0.0 & 0.1 & 0.1 \\
\hline & $\mathbf{F}$ & 93.8 & 91.2 & 94.7 & 93.5 & 0.3 & 2.3 & 1.2 & 2.3 \\
\hline & $\mathbf{G}$ & 93.7 & 94.4 & 93.9 & 94.0 & 0.3 & 0.4 & 0.1 & 0.4 \\
\hline & $\mathbf{H}$ & 92.9 & 93.0 & 93.4 & 93.1 & 0.2 & 0.1 & 0.3 & 0.3 \\
\hline & 1 & 91.9 & 91.8 & 92.2 & 92.0 & 0.0 & 0.2 & 0.2 & 0.2 \\
\hline & $\mathbf{J}$ & 93.5 & 94.1 & 93.6 & 93.7 & 0.2 & 0.4 & 0.1 & 0.4 \\
\hline & $x$ & 91.6 & 92.6 & 92.4 & 92.2 & 0.6 & 0.4 & 0.2 & 0.6 \\
\hline
\end{tabular}

Table 6: Impact sound pressure levels for three individual impacts using the small impactor with a drop height of $50 \mathrm{~cm}$. The table shows results for each of the hammer tips used and for every floor covering tested, including the bare floor. Column 6 shows the mean sound pressure level and column 10 shows the maximum deviation $\Delta$ from the mean sound pressure level for the three impacts shown. 


\section{Influence of Measurand}

As a final note on uncertainties, in addition to the different impactor types, it is also useful to briefly consider the uncertainties associated with the different quantities measured during the tests, i.e. sound pressure level, force and the acceleration of the floor. Thus, in this sub-section additional plots are provided that demonstrate the repeatability of impacts using the small impactor when the sound pressure, acceleration and force was used as the measurand. In Figure 22 the repeatability of the sound pressure is shown, in Figure 23 the acceleration and in Figure 24 the force.
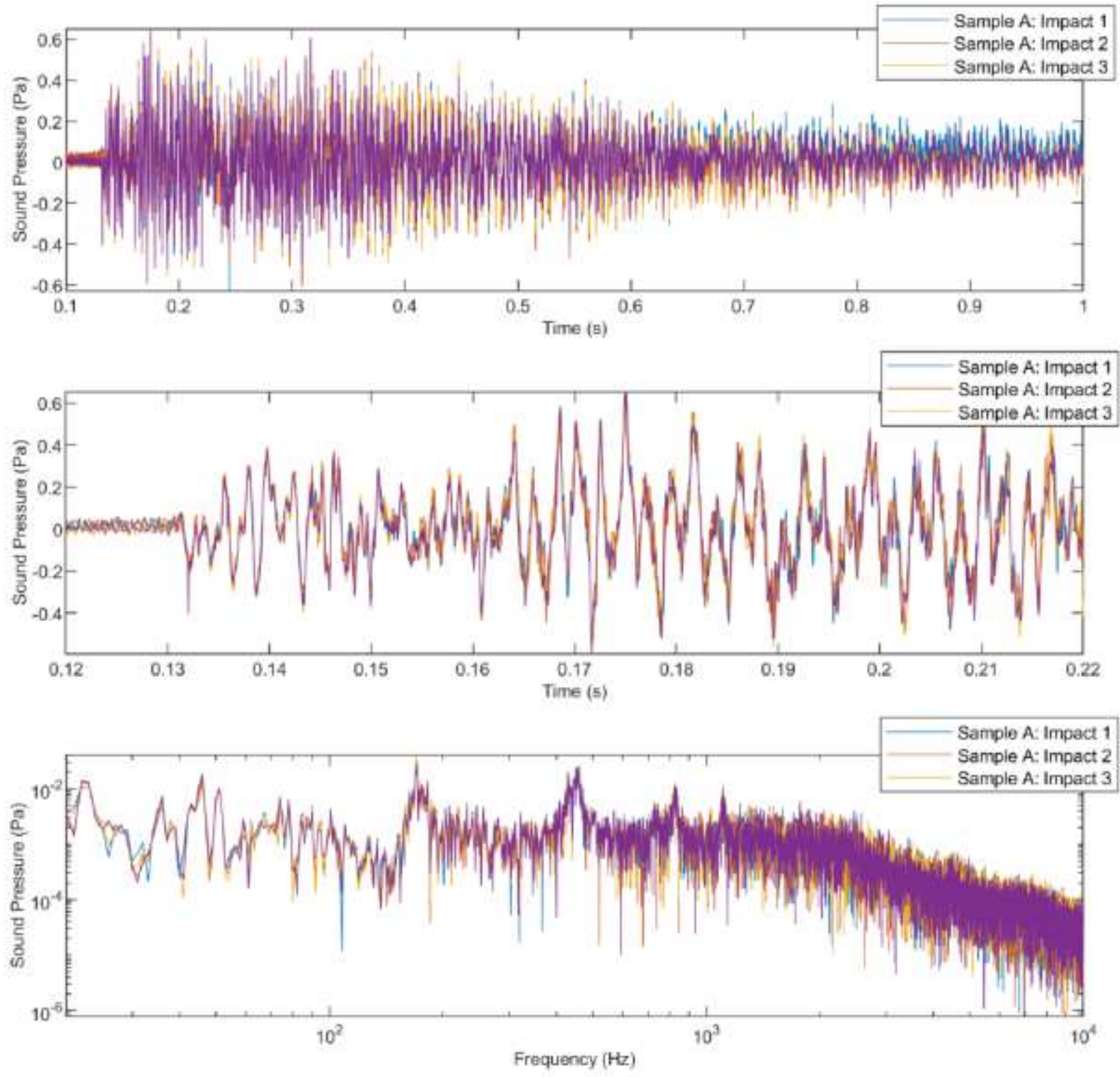

Figure 22: Repeatability of the small impactor with steel face for three different impacts when the measurand used is the sound pressure level in the reverberation chamber. The upper plot is sound pressure in the time domain and the middle plot is a close up of a shorter timescale of this same curve. The bottom plot shows the corresponding narrow band frequency spectra for the same three impacts as measured by one of the chamber microphones. 

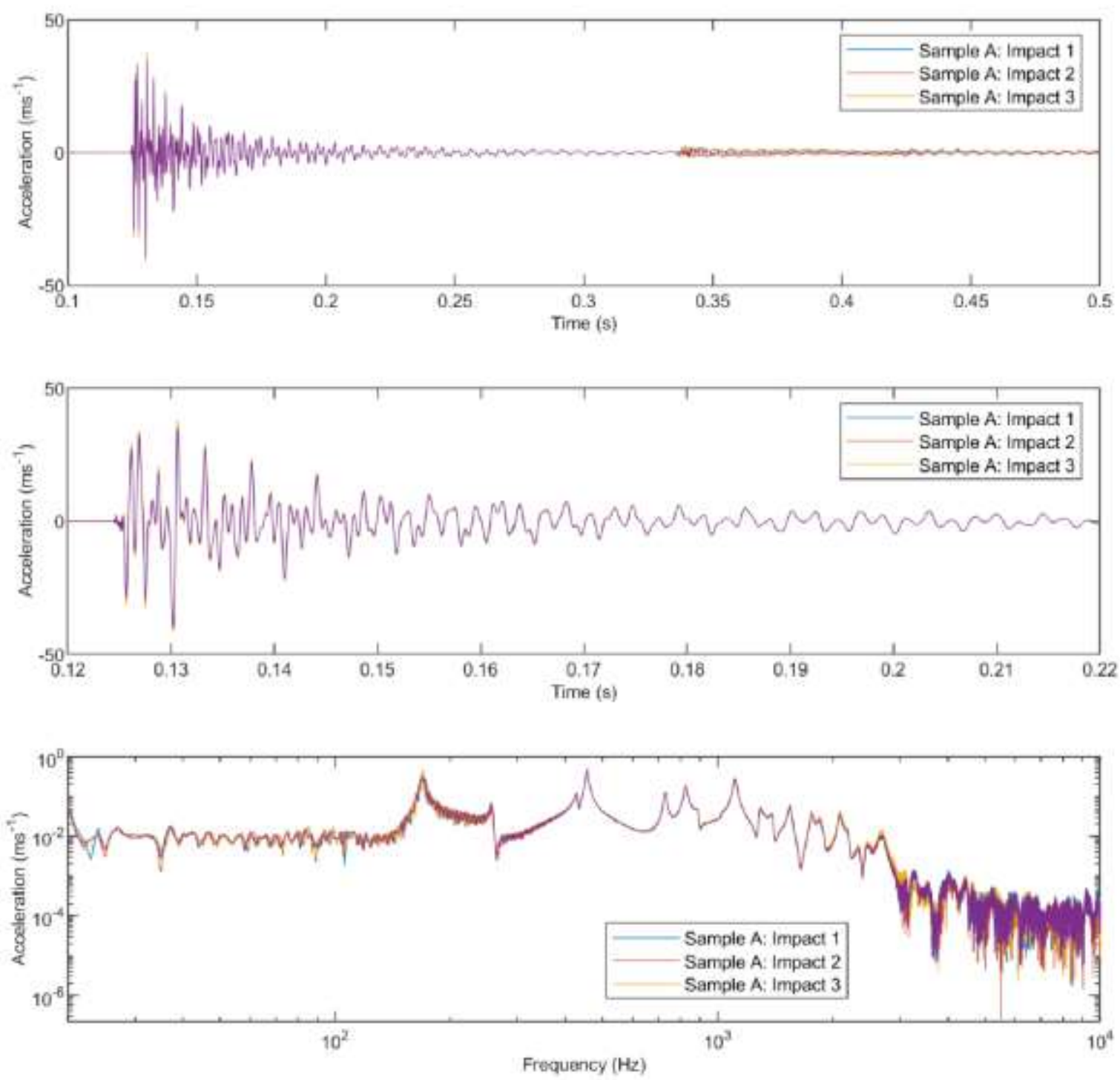

Figure 23: Repeatability of the small impactor with steel face for three different impacts when the measurand used is the acceleration of the floor. The upper plot is acceleration in the time domain and the middle plot is a close up of a shorter timescale of this same curve. The bottom plot shows the corresponding narrow band frequency spectra for the same three impacts as measured by an accelerometer at the corner of the floor.

Perhaps the most surprising of the results shown are for the force and the acceleration in the time domain which show that the means of excitation is highly repeatable for this particular floor sample. Less repeatable is the sound pressure level. This may be due to higher background noise, perhaps due to the drop test mechanism and the presence of an operator plus laptop computer in the chamber. Nevertheless, the repeatability is still good when the sound pressure is used as the measurand and this could no doubt be improved with small modifications to the test setup and 
procedure.
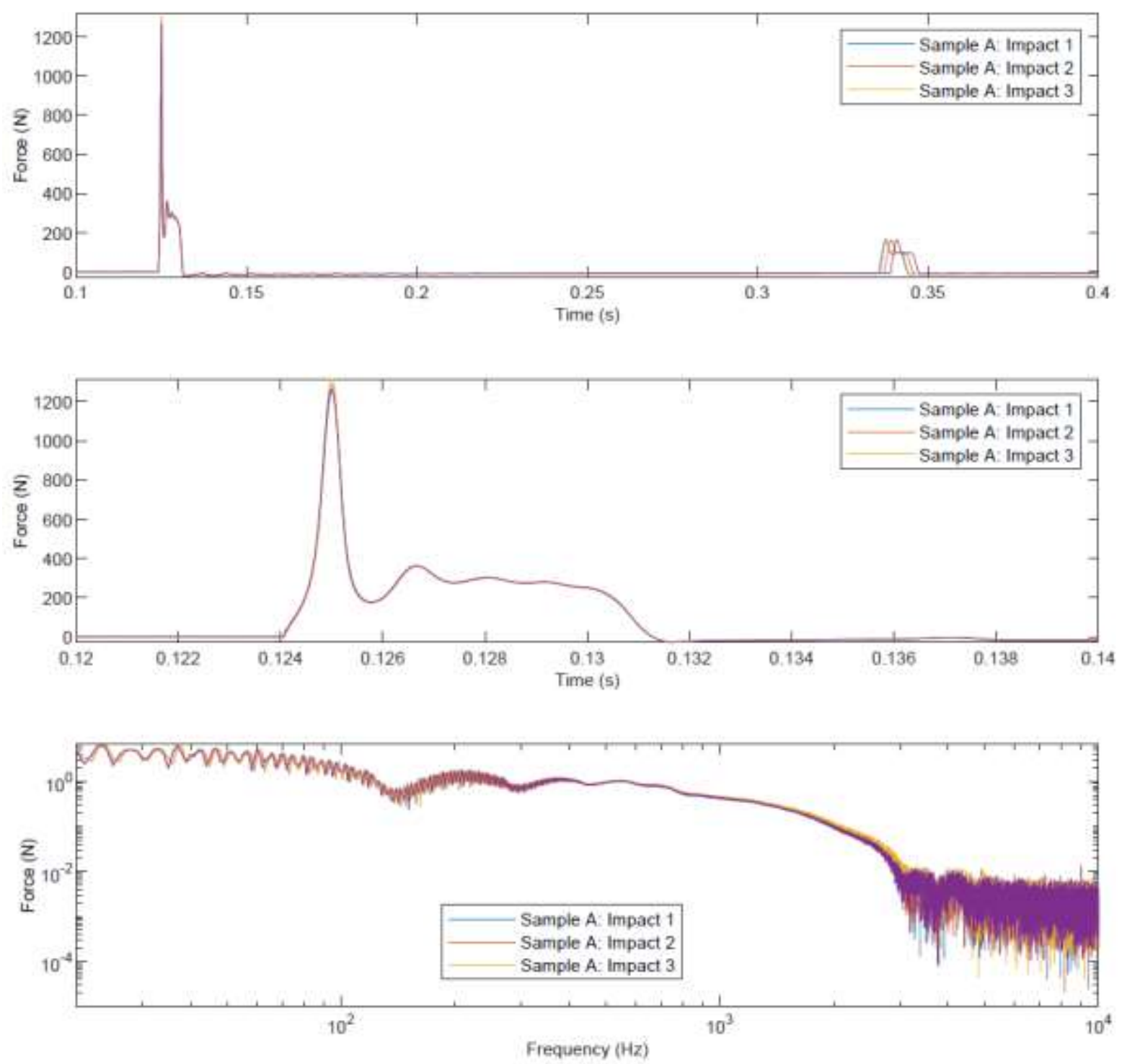

Figure 24: Repeatability of the small impactor with steel face for three different impacts when the measurand used is the impact force. The upper plot is the force in the time domain and the middle plot is a close up of a shorter timescale of this same curve. The bottom plot shows the corresponding narrow band frequency spectra for the same three impacts as measured by the force transducer attached to the hammer tip.

The results shown imply that there may be additional advantages to using force or acceleration as a quantity for rating in-room impact noise reduction. Note that the use of acceleration is already standardised for the rating of transmitted impact noise in ISO 16251-1 [20]. The drawback of acceleration and force for in-room impact noise however is that they do not fully reflect in-room 
sound pressure levels when a floor covering is not locally reacting. As such, unless some form of correction factor is used, the force and the acceleration can only be used for certain floor coverings to rate in-room impact noise which is an unfortunate limitation. For structure borne impact noise, this would be less of a concern.

\section{Concluding Remarks}

The in-room impact sound reduction of a range of different floor coverings has been measured for a range of different impactor types using bespoke laboratory setups. The conventional tapping machine typically used for this type of assessment was not employed in the study primarily because it produces to much mechanical self-noise. Furthermore, for in room impact noise reduction, one is not just concerned with footfall noise but also falling objects: some of which may ring or produce significant acceleration noise themselves. The primary purpose of the study was to investigate how the rank order or floor coverings varied depending on the type of impactor. Because one cannot expect a measured in room impact noise reduction for a specific impactor to be observed for other impactor types this rank order is perhaps of more interest than impactor specific reductions if it is found to be consistent. In this way a better/worse performing product could at least be easily identified with respect to other products on the market.

From the investigation it was found that although the in-room impact sound reduction varied widely from case to case (impactor type), the general rank order of the impact sound reductions did not vary significantly. This therefore implies that regardless of the test employed, a similar rank order will be obtained, and that the ideal test procedure may not necessarily be one that is representative of everyday life, but one which gives the greatest resolution between floor coverings. There are however some provisos on this, for example, floor coverings that are not locally reacting are likely to be an exception to this rule (laminates in particular) and this was in fact observed for one of the floor coverings tested; Sample A, which was a foam backed rubber floor covering. It is likely therefore that different categories of floor coverings may exist that have different rank orders. For floor coverings that are sensitive in this way it may be possible to employ a correction factor but this was not investigated here and would therefore be a subject for further work.

In addition to testing a range of impactor types a range of measurement methods was also investigated including: force, acceleration and sound pressure. The measurement of impact force, as opposed to sound pressure, was found to be a potentially appealing alternative means of rating in room impact noise reduction because it avoids completely the requirement for specialist test chambers and because large differences were observed between similar floor covering types; 
potentially making differences between floor covrerings easier to resolve. The drawback to this approach is that it is not possible to capture the acceleration noise of the floor covering itself, which could be an issue for rating floor coverings that have a hard surface coupled to a soft backing such as laminates. This was not found to be a particularly concerning issue for the floor coverings tested here, but for wood floor coverings on a soft underlay this may not be the case. Again, in such instances a correction factor could perhaps be employed but this would require further investigation.

\section{Acknowledgements}

This research study was funded by NORA systems $\mathrm{GmbH}$, a leading global manufacturer of commercial rubber floor covering systems. 


\section{References}

[1] BS EN ISO 10140-3:2010, Acoustics. Laboratory measurement of sound insulation of building elements. Measurement of impact sound insulation, (2011).

[2] BS EN ISO 717-2:2013, Acoustics. Rating of sound insulation in buildings and of building elements. Impact sound insulation, (2013).

[3] ASTM E492. Standard Test Method for Laboratory Measurement of Impact Sound Transmission through Floor-ceiling Assemblies using the Tapping Machine.

[4] ASTM E2179. Standard Test Method for Laboratory Measurement of the Effectiveness Of Floor Coverings In Reducing Impact Sound Transmission Through Concrete Floors.

[5] Mackenzie, D., \& Galbrun, L. (2007). Noise levels and noise sources in acute care hospital wards. Building Services Engineering Research \& Technology, 28(2), 117-131.

[6] BS EN 16205:2013, Laboratory measurement of walking noise on floors, (2013).

[7] Scholl, W., Wittstock, V., Bietz, H., \& Stange-Kölling, S. (2015). Measurement of Walking Noise on Floor Coverings. Building Acoustics, 22(1), 1-27.

[8] Scholl W. Impact sound insulation: The standard tapping machine shall learn to walk!. Building Acoustics. 2001 Dec;8(4):245-56.

[9] Bütikofer, R. (2010). New acoustic test procedure for hard floor covering systems with soft underlay. Acta Acustica United with Acustica, 96(3), 494-504.

[10] Scholl, W., \& Maysenhölder, W. (1999). Impact sound insulation of timber floors: Interaction between source, floor coverings and load bearing floor. Building Acoustics, 6(1), 43-61.

[11] Richards, E. J., Westcott, M. E., \& Jeyapalan, R. K. (1979). On the prediction of impact noise, I: Acceleration noise. Journal of Sound and Vibration, 62(4), 547-575.

[12] Richards, E. J., Westcott, M. E., \& Jeyapalan, R. K. (1979). On the prediction of impact noise, II: Ringing noise. Journal of Sound and Vibration, 65(3), 419-451.

[13] Jakob, A., Volz, R., \& Möser, M. (2005). Investigation of the physical mechanism of walking noise radiation of laminate floor-coverings. Building Acoustics, 12(3), 141-163.

[14] Scholl, W., Ciszewski, R., \& Wittstock, V. (2013). Revision of ISO 717: why not use impact sound reduction indices instead of impact sound pressure levels? Part 2: application to different impact sources. Acta Acustica united with Acustica, 99(6), 917-930. 
[15] Cremer, L., Heckl, M., \& Petersson, B. (2005). Structure-Borne Sound. Berlin, Heidelberg: Springer Berlin Heidelberg.

[16] Dobson, B. J., and E. Rider. "A review of the indirect calculation of excitation forces from measured structural response data." Proceedings of the Institution of Mechanical Engineers, Part C: Mechanical Engineering Science 204.2 (1990): 69-75.

[17] Elliott, A. S., et al. "In-situ source path contribution analysis of structure borne road noise." Journal of Sound and Vibration332.24 (2013): 6276-6295.

[18] BS EN ISO 3744:2010, Acoustics. Determination of sound power levels and sound energy levels of noise sources using sound pressure. Engineering methods for an essentially free field over a reflecting plane, (2011).

[19] BS EN ISO 3741:2010, Acoustics. Determination of sound power levels and sound energy levels of noise sources using sound pressure. Precision methods for reverberation test rooms, (2010).

[20] ISO 16251-1 (Acoustics -- Laboratory measurement of the reduction of transmitted impact noise by floor coverings on a small floor mock-up -- Part 1: Heavyweight compact floor 